\title{
The catalytic effect of dimethyl disulfide on coke formation on high temperature alloys: myth or reality?
}

Manjunath Patil ${ }^{1}$, Stamatis A. Sarris ${ }^{1}$, Kim Verbeken ${ }^{2}$, Marie-Françoise Reyniers ${ }^{1}$, Kevin M. Van Geem ${ }^{1, *}$

${ }^{1}$ Ghent University, Laboratory for Chemical Technology, Technologiepark 125, 9052 Gent, Belgium.

${ }^{2}$ Ghent University, Department of Materials, Textiles and Chemical Engineering, Technologiepark 46, 9052 Gent, Belgium

*Corresponding author: Technologiepark-Zwijnaarde 125, 9052 Gent, Belgium; $\underline{\text { Kevin.VanGeem@UGent.be }}$

\begin{abstract}
:
The selection of the reactor material with the lowest coking tendency can result in substantial economic benefits for the steam cracking process. One of the remaining unresolved points of discussion is what the influence is of sulfur addition, in particular dimethyl disulfide (DMDS) on various steam cracking reactor alloys with varying Ni-Cr content. To shine some new light on this topic, an extensive thermogravimetric study was performed in a jet stirred reactor set up (JSR) evaluating on-line the coking behavior of four Ni-Cr-Fe alloys under industrially relevant ethane cracking conditions. For each material, the effect of pre-oxidation/pretreatment with and without the presence of DMDS was evaluated, with as objective to minimize the materials coking tendency. The coking rates show that an increased $\mathrm{Ni}-\mathrm{Cr}$ content of the material improves the coking rates by a factor 2 or more under the studied process conditions. By continuously feeding DMDS, all non Al-containing alloys indicate 7 times higher coking rates than the Blank runs, while the carbon oxide(s) formation is suppressed by a factor 5 . In comparison to continuous addition and presulfiding with DMDS, labelled as ' $\mathrm{CA}+$ PreS' experiments, the Al-containing alloy outperforms itself significantly when pre-oxidized at 1223
\end{abstract}


$\mathrm{K}$ by $50 \%$ in terms of coking rates. The results indicate that $\mathrm{Al}$ addition to Ni-Cr-Fe alloys improves their anti-coking performance, provided that the pre-oxidation temperature is higher than for materials without Al. The overall results from coking rates and off-line SEM and EDX analysis for the coked coupons showed an outstanding oxidation homogeneity for the $40 / 48 \mathrm{Cr}$ $\mathrm{Ni}$ alloy, which was better than the Al-containing alloy at lower pre-oxidation temperatures.

Keywords: steam cracking, presulfiding, pre-oxidation, jet stirred reactor, anti-coking technologies, High-Temperature Alloys, Al-containing alloys

\section{Introduction}

Minimization of coke formation on the inner wall of tubular reactors in steam cracking furnaces is the most relevant challenge to improve the time on stream and thus the economics of the process $^{1-2}$. In steam cracking plants more than $90 \%$ of carbon dioxide emissions can be directly related to energy consumption of the endothermic conversion in cracking furnaces ${ }^{3}$. However, climate change makes it mandatory to replace fossil fuels with electricity, reactor materials will still be of high importance, in particular when moving a chemical industry that works based on Joule effect ${ }^{4}$. To avoid operation of the furnace above the metallurgical maximum allowable temperature or at the maximum pressure drop, an on-line decoking procedure of about 48 hours using steam, steam and hydrogen ${ }^{5}$ or - more commonly - a steam/air mixture ${ }^{6-7}$ is applied. The aim of decoking is to rapidly, safely and completely remove the coke formed on the coil, creating a continuous oxide layer at the interface of the gas and coil. Alternative decoking technologies have also been developed over the past years for tubular heaters or reactors ${ }^{8-17}$ while industrial best practices on rapid decoking techniques with improved control to reduce radiant coil damages have been summarized by Sullivan ${ }^{6}$. Next to these techniques innovative surface technologies have even received more attention in the field, such as high performance 
alloys ${ }^{18-19}$ and coatings ${ }^{20-22}$. The material cost of the reactors made out of these high temperature alloys is substantial and hence maximizing their lifetime and anti-coking performance is essential. The use of additives, especially sulfur-containing ones, as pretreatment and/or continuous addition is costly but widely applied ${ }^{23-39}$. However, its effect is still one of the big myths with believers and disbelievers. To make it even more complex, the material composition (amount of $\mathrm{Cr}, \mathrm{Mn}$ and $\mathrm{Si}{ }^{40}$ ), pretreatment (oxidative, reductive, oxidants, etc.) and their effect on carbon oxides formation also play an important role in reducing coking rates. Accurately calculating carbon oxides formation during effluent analysis, to reduce mass and molar balance closure discrepancies, can help overcome instabilities in the experimental dataset, demonstrated by Quantis ${ }^{41}$. Classically, an oxidative pretreatment on the inner side of the reactor material is applied on-line before the start of the process, but the different elemental composition of each alloy will affect the characteristics of the oxide layer and eventually lead to different coking behavior ${ }^{18}$. The duration of pretreatment has an effect on the rate of coke formation that varies between 30 minutes and 4 hours or longer at temperatures in the range of 873 to $1223 \mathrm{~K}^{42}$.

Horsley et al. ${ }^{43}$ observed that a significant enrichment of $\mathrm{Cr}$ and $\mathrm{Mn}$ oxides at the surface of the alloy - namely $\mathrm{MnCr}_{2} \mathrm{O}_{4}, \mathrm{MnO}$ or $\mathrm{Cr}_{2} \mathrm{O}_{3}$, was followed by a decreased absolute coke amount. Different oxidizing gas mixtures were tested on Incoloy 800 coupons by Luan and Eckert ${ }^{44}$ showing that temperature, duration, and composition of the pretreating gases are the predominant factors affecting the surface composition and thickness of the formed layers after pretreatment. Jakobi and Karduck ${ }^{45-46}$ evaluated different spun cast alloys in industrially relevant start-up conditions. They found that on chromia forming alloys a protective and complex system of oxide layers is formed consisting of a chromium-manganese spinel on top of a chromia layer and with a thin layer of $\mathrm{SiO}_{2}$ at the oxide-metal interface forming a total oxide layer of $1 \mu \mathrm{m}$ on top. Al-containing alloys formed a thin protecting $\mathrm{Al}_{2} \mathrm{O}_{3}$ layer with a 
thickness of $100 \mathrm{~nm}$ showing increased corrosion and carburization resistance, especially if the temperature exceeds $1173 \mathrm{~K}$. Similarly, Asteman and Hartnagel ${ }^{47}$ investigated the impact of the $\mathrm{Al}$ and $\mathrm{Cr}$ content in alloys and concluded that the $\mathrm{Al}_{2} \mathrm{O}_{3}$ forming alloy, containing $4 \mathrm{wt} \%$ $\mathrm{Al}$ (NiCr25A14), has the best preoxidation properties with minimal spallation, compared to the $\mathrm{Cr}_{2} \mathrm{O}_{3}$ former $(\mathrm{NiCr} 28)$, even after $500 \mathrm{~h}$ isothermal exposure. After the radiant section, the process gas is rapidly cooled in a transfer line exchanger (TLE) and the coking rates in TLE are observed to have a significant influence on the partial pressures of water and hydrogen ${ }^{48}$. This study focuses on the comparison of four high temperature alloys under industrially relevant cracking conditions; three, with primarily a difference of the Ni-Cr content, starting from a classical 25/35 CrNi alloy, and additionally an Al-containing alloy with 4\% of Al was tested as well. The role of sulfur, cyclic aging of the alloys and pre-oxidation at high temperature is studied. Therefore the coking resistance of all materials is thermogravimetrically analyzed, and for the first time detailed experimental coking rates measured under representative gas phase atmospheres are provided, supported by surface and cross-sectional SEM and EDX observations to assist the interpretation of the experimental results. This allows to rank the materials according to their expected industrial performance.

\section{Experimental section}

\subsection{Electrobalance Setup}

The jet stirred reactor set-up has been extensively described in previous work ${ }^{18-19,42}$, therefore, only a brief description is given here. The set-up consists of three parts: a feed section, a reactor section and an analysis section as shown in Figure 1. The mass flow rates of gasses and water are controlled by thermal mass flow controllers. All the lines in contact with sulfur are Sulfinert ${ }^{\circledR}$-treated ${ }^{49}$. The water is vaporized in an evaporator, mixed with the heated hydrocarbon feedstock and further heated before entering the reactor inlet at a temperature of 
$903 \mathrm{~K}$. A jet stirred reactor made out of quartz is used, with a flat coupon in the center of the JSR suspended from the arm of an electrobalance. The coupon dimensions are $10 \mathrm{~mm} \times 8 \mathrm{~mm}$ $\times 1 \mathrm{~mm}$. The mass changes are tracked over time with a frequency of $1 \mathrm{~Hz}$. Subsequently, the reactor effluent is quenched to prevent further cracking and its composition is measured with two gas chromatographs (GC) using nitrogen as internal standard i.e. a refinery gas analyzer dedicated to the analysis of components with less than 5 carbon atoms and a TRACE ${ }^{\mathrm{TM}}$ Ultra GC detecting hydrocarbons ranging from methane to naphthalene. For ethane cracking, no heavier products are measured than naphthalene. In detail, from the peak areas of the TCDchannel, experimentally determined calibration factors and the known amount of nitrogen, the flows of hydrogen, methane, carbon oxides and C2 hydrocarbons are calculated. The calculated methane flow is subsequently used as internal standard for the flow determination of higher hydrocarbons on the FID-channels.

\subsection{Experimental procedures, materials and conditions}

The overall variation in experimental conditions is summarized in Figure 2. Four different alloys are evaluated under a broad range of industrially relevant conditions as summarized in Table 1 . The first is the classical $25 / 35 \mathrm{CrNi}$. Next to that, two innovative alloys with a higher Cr-Ni content (35/45 and 40/48) and one Al-containing alloy are studied. For all alloys, the coupons are cut from the inner side of an industrial coil using wire-cut Electrical Discharge Machining (EDM) with an accuracy of $1 \mu \mathrm{m}$. Operating procedures and conditions used in this work are summarized in Table 1. To mimic aging behavior, the experiments consisted of eight coking cycles, the first three involved $6 \mathrm{~h}$ of cracking and steam/air treatment followed by four short cycles of $1 \mathrm{~h}$ of cracking and steam/air treatment and a last coking cycle of 6 hours. The heating ramp used during stabilization, heating and cooling of the set-up is $300 \mathrm{~K} \mathrm{~h}^{-1}$. For all the performed experiments, an initial pre-oxidation step for 14 hours in the presence of air at $1023 \mathrm{~K}$ or $1223 \mathrm{~K}$ is performed before the first coking cycle. As next steps after a coking cycle, 
the pretreatment procedure consists of a steam or steam/air treatment. After every coking cycle $\left(\mathrm{CC}_{\mathrm{n}-1}\right)$, steam or steam/air treatment is performed in order to burn the coke formed on the sample and regenerate the oxides formed on the sample surface ${ }^{42}$.In case that presulfiding is applied, it is performed after these pretreatment steps, just before steam cracking.

The experiments with a presulfiding step before the coking cycles are labeled with "PreS", 500 ppmw $/ \mathrm{H}_{2} \mathrm{O}$. During experiments with continuous addition of DMDS, labeled with "CA", 41 ppmw S/HC diluted in the water is fed; $\mathrm{CA}$ and PreS values correspond as a reference to all the studies that were performed with similar process conditions to study coking rates and limit the formation of carbon oxides ${ }^{21,42,50-51}$. The reactor temperature is set throughout the cracking runs at $1173 \mathrm{~K}$, a value that is reached within 5 minutes after introducing the cracking mixture in the reactor. The standard experiment, without any addition of DMDS before or during cracking and at the typical temperature of $1173 \mathrm{~K}$ is noted as "Blank" which serves as a reference experiment to evaluate the effect of DMDS.

After steam cracking for 6 hours, the reactor temperature is set to $1023 \mathrm{~K}$ and the flow rate of ethane and steam is set to zero, leaving only helium to purge through the reactor. After the last coking cycle, for the reactor cooling down to room temperature, a He flow of $0.6 \cdot 10^{-6} \mathrm{~kg} \cdot \mathrm{s}^{-1}$ is used as inert gas while the furnace ramp is set to $100 \mathrm{~K}$ per hour.

Also a set of experiments has been carried out where cyclic aging of the materials was studied. Here, pre-oxidation between every coking cycle, labelled as "Pre-O all CC" was performed. All materials are pre-oxidized in presence of air for 12 to 14 hours after the end of every coking cycle at $1023 \mathrm{~K}$. Cyclic-aging would metallurgically age the coupons and also ensure that the coupon develops sufficient oxide as a barrier to coke formation before the beginning of a coking cycle. Pre-oxidation between every coking cycle is followed with similar steam cracking conditions as labelled for "Blank" and "CA+PreS". For all materials, the "initial" pre-oxidation before the first coking cycle is performed at $1223 \mathrm{~K}$ to enable full development of the surface 
alpha-alumina layer on the Al-containing alloy ${ }^{39}$. After pre-oxidation at $1223 \mathrm{~K}$, the test is performed similar to the "CA+PreS" labelled experiment during a coking cycle.

\subsection{Determination of the coking rate}

The coke deposition on each sample is measured over time by continuously weighing the mass of the sample. This allows the determination of the total amount of coke after every coking cycle, as well as the calculation of the initial catalytic coking rate and the asymptotic pyrolytic coking rate. Similar to previous work ${ }^{18-19,42}$, the coking rate is determined as:

$$
\mathrm{R}_{\mathrm{c}}=\frac{\mathrm{m}_{\mathrm{t}_{2}}-\mathrm{m}_{\mathrm{t}_{1}}}{\mathrm{t}_{2}-\mathrm{t}_{1}} \frac{1}{\mathrm{~s}}
$$

where $\mathrm{R}_{\mathrm{c}}$ is the coking rate in $\mathrm{kg} \cdot \mathrm{s}^{-1} \cdot \mathrm{m}^{-2}, \mathrm{mt}_{\mathrm{j}}$ the mass of coke at time $\mathrm{j}$ in $\mathrm{kg}, \mathrm{t}_{\mathrm{j}}$ the experimental time at time $\mathrm{j}$ in $\mathrm{s}$ and $\mathrm{S}$ the surface area of the coupon in $\mathrm{m}^{2}$.

The value of the coking rate measured between 15 minutes and 60 minutes is defined as the initial or catalytic coking rate, i.e. characterizing the catalytic coking behavior of the sample. The asymptotic coking rate is related to the pyrolytic coking mechanism and is reported as the measured coking rate between the $5^{\text {th }}$ and $6^{\text {th }}$ hour of cracking.

\subsection{Scanning Electron Microscope (SEM) and Energy Dispersive X-ray (EDX) Analysis}

Scanning Electron Microscopy (SEM) of the coupons is performed using a JEOL, type JSM7600F, with a Schottky field emission gun as an electron source and Energy Dispersive X-ray Spectroscopy (EDX) is used to obtain information regarding the morphology and to perform chemical analysis. The top surface analyses give qualitative information of the elemental composition of the surface, while cross sectional mappings evaluate the uniformity of the oxides generated during each experiment. The surface composition is an average of EDX analysis on two different and representative locations of the examined coupons. 


\section{Experimental results and discussion}

The coking data of the different experiments are summarized in Table 3 to Table 6 . The elemental composition of fresh alloys measured using EDX are shown in Table 7. These results show that by adding DMDS during steam cracking an increase of the coking rates and a decrease in the formation of the carbon oxides is noted for all the materials, which is in line with previous work. By enriching the alloy composition in $\mathrm{Cr}$ and $\mathrm{Ni}$ concentration the observed coking rates drop. Most alloys showed a quite pronounced stability during the cyclic aging in terms of coking rates, except for the experiments with initial pre-oxidation at $1223 \mathrm{~K}$. The gas effluent analyses of the performed experiments is provided by the Supporting Information. In general, minor differences can be observed for the gas effluent composition when changing the alloy composition under the same conditions, while no differences are observed during the cyclic aging and during each coking cycle per material. Therefore, only the average gas phase composition is reported. In what follows, a more detailed analysis of the experimental observations is given, focusing on the individual effect of the investigated parameters such as pretreatments, DMDS, Ni-Cr content and Al addition.

\subsection{Influence of sulfur}

\section{a) Blank experiments}

In Figure 3 and Table 3 the coking behavior of the four different alloys in the absence of DMDS at $1173 \mathrm{~K}$, is shown. It should be stressed that industrially the use of DMDS cannot be avoided as it is needed to suppress the pronounced carbon oxides formation by steam reforming. However, to thoroughly and fundamentally evaluate the effect of the addition of DMDS before or during cracking this type of experiment is used as a reference. Under the tested conditions, the 40/48 CrNi alloy outperforms the rest of the alloys when considering only the initial catalytic coking step. A similar anti-coking performance is observed for the $35 / 45 \mathrm{CrNi}$ alloy. 
The 25/35 CrNi alloy shows a 20 to $30 \%$ worse coking behavior than the former. The worst performance is noted for the Al-containing alloy, having overall 2 to 3 times more pronounced coking rates. However, given the fact that DMDS is always used in industry, this negative experimental observation should not necessarily be considered discouraging for its industrial use. Nevertheless, it shows that sulfur dosing for all the alloys is extremely important with observed CO yields from $0.045 \mathrm{wt} \%$ up to $0.06 \mathrm{wt} \%$, the latter for Al-containing alloy. For economic reasons one would go to the minimal acceptable sulfur doses that still gives low $\mathrm{CO}$ yields."

The coking trends remain the same for the asymptotic coking rate, with overall reduced values in comparison with the initial rates. It is known that $\mathrm{Ni}$ and $\mathrm{Fe}$ are coke formation precursors, while $\mathrm{Cr}$, Mn and Al, which are associated with dense passivating oxides, can be responsible for an improved anti-coking behavior of an alloy ${ }^{18}$. The elemental composition of the coked samples is in line with the coking observations, with the Al-containing alloy having the most pronounced amount of $\mathrm{Fe}$ and $\mathrm{Ni}$ on its surface, as shown in Table 8. Also, the sum of $\mathrm{Cr}$ and $\mathrm{Mn}$ in the non-Al-containing alloys is more than $85 \mathrm{wt} \%$ for all cases, while for the Alcontaining alloy the sum of $\mathrm{Cr}$ and $\mathrm{Al}$ is less than $80 \mathrm{wt} \%$, implying that its poor anti-coking behavior can be attributed to this feature - if one simplifies anti-coking behavior to this variable only. Further confirmation by additional experimental work is needed to make sure that this statement can be generalized.

From the cross section analyses in Figure S. 1 to Figure S.4 in the Supporting Information, it is clear that the $35 / 45 \mathrm{CrNi}$ alloy has a thicker oxide (approximately $3 \mu \mathrm{m}$ ) formed on its surface than the $25 / 35 \mathrm{CrNi}$ alloy (approximately $1 \mu \mathrm{m}$ ). The thickness of the Al-containing alloy is roughly $1 \mu \mathrm{m}$ consisting mainly of $\mathrm{Al}$ and $\mathrm{O}$. A thick (approximately $3 \mu \mathrm{m}$ ) and very homogeneous oxide mainly of $\mathrm{Cr}$ and $\mathrm{O}$ is observed for the 40/48 CrNi alloy. 


\section{b) Continuous addition experiments}

Comparing the catalytic coking behavior of the four different alloys under CA conditions, see Figure 4 top and Table 4, shows large differences in comparison with the results discussed in Section 3.1 (a). The Al-containing material is the only one that forms less coke when DMDS is continuously added than in its absence. The Al-containing alloy is now only outperformed by the $40 / 48 \mathrm{CrNi}$ material, which cokes $20 \%$ to $50 \%$ less depending on the coking cycle. Overall, the ranking among of the Fe-Ni-Cr alloys remains the same as in the Blank runs, but with more pronounced differences. By continuously feeding DMDS, all non Al-containing alloys indicate roughly 7 times higher coking rates than the Blank runs, while the carbon oxide(s) formation is suppressed by a factor 5 .

The 40/48 CrNi alloy cokes almost 2 times less than the 35/45 CrNi alloy and 3 to 5 times less than the $25 / 35 \mathrm{CrNi}$ alloy. The Al containing alloy is not able to outperform the CrNi alloys in the current process conditions, despite the fact that results obtained by other research groups have indicated that the alpha-alumina oxide layer is developed at or over $1223 \mathrm{~K}^{45-47}$. Similar trends, but less pronounced, are noted for the asymptotic coking rates of all alloys.

The trends in the elemental composition of the tested coked samples - Table 9 - remain similar with those observed for the Blank runs, which indicates that the elemental composition of a well pretreated surface is affected mainly by the steam/air treatment and pretreatment procedure. In Figure S. 5 to Figure S. 8, the cross sectional images of the coked samples after application of aging with continuous addition of DMDS are illustrated. In comparison with the blank conditions, the $25 / 35$ and $35 / 45 \mathrm{CrNi}$ alloy show similar oxide thicknesses of approximately $3 \mu \mathrm{m}$. For the Al-containing alloy the oxide thickness seems to be reduced to less than $1 \mu \mathrm{m}$. The oxide thickness for the $40 / 48 \mathrm{CrNi}$ alloy appears also to be stable, with oxides consisting of both $\mathrm{Cr}$ and Mn oxides ${ }^{39}$. 


\section{c) Presulfiding and continuous addition effect}

The presulfiding effect is evaluated for both the Blank and CA runs. Initially, by comparison of Figure 3 and Figure 5, the presulfiding treatment step seems to have a negligible effect on the coking behavior of the Al-containing alloy, for neither its catalytic or pyrolytic coking behavior. For the non-Al-containing alloys, a 2 to 3 times increase is observed after including the presulfiding step before cracking. Nevertheless, the Al-containing alloy performs worse in terms of asymptotic coking rate than the 40/48 CrNi alloy. Once more, the performance established in terms of anti-coking behavior remains the same; the $25 / 35 \mathrm{CrNi}$ material performs the worst, while the $40 / 48 \mathrm{CrNi}$ is the best. No additional significant effect of presulfiding when combined with continuous addition of DMDS can be observed on the carbon oxides suppression. In case of an only presulfided sample, the carbon monoxide yields for all $\mathrm{Ni}-\mathrm{Cr}$ alloys are lower by $20 \%$ when compared to the values from the Blank run, except Alcontaining alloy where no change is observed, as shown in the supporting information section. In the case of "CA" and "CA+PreS" experiments the average yields of carbon oxide(s) remain the same. Presulfiding thus does not seem to improve any performance for the conditions and materials tested. The comparison of elemental composition on the surface of the sample from Blank run in Table 8 to presulfided samples in Table 10, it is obvious that the presulfided samples are enriched with $\mathrm{Ni}$ and Fe on the surface, which explains their pronounced coking rates. That is not the case for the Al-containing alloy that shows increased amounts of $\mathrm{Al}$ on the surface layer.

While comparing Figure 4 and Figure 6, it is clear that when presulfiding is combined with continuous addition of DMDS, it has a limited effect in terms of coking rates causing in most of the cases an increase of roughly 10 to $20 \%$. Overall, it seems that under these conditions, the 25/35 CrNi alloy cokes at least 2 times more than the other materials. The best anti-coking performance is found for the $40 / 48 \mathrm{CrNi}$ alloy, giving a factor two lower coking rate than the 
Al-containing material that is performing roughly $10 \%$ better than the third, the $35 / 45 \mathrm{CrNi}$ alloy.

The elemental composition of the CA + PreS samples is almost the same as for the PreS ones, as shown in Table 10 and Table 11, verifying once more that the elemental surface composition is a strong function of the pretreatment. For all cases studied, the $25 / 35$ and $35 / 45 \mathrm{CrNi}$ alloys show a uniform surface oxidation with the latter indicating thicker oxides. Overall, the oxide thickness is decreased by including a presulfiding step before cracking for all alloys, but no significant effect on the oxide homogeneity is noticed except for the $25 / 35 \mathrm{CrNi}$ which has minor deficiencies in the top oxide. For the Al-containing alloy, also $\mathrm{Cr}$ is present in the formed oxides. Observing Figure S. 13 to Figure S. 16, the decrease of the oxides thickness after application of a presulfiding step is also noticed for all alloys when continuous addition of DMDS is applied during steam cracking. The homogeneity of the oxide scale is still acceptable, leaving no catalytic $\mathrm{Fe}$ and $\mathrm{Ni}$ in contact with the gas phase that would promote coke formation.

\subsection{Influence of cyclic aging}

Cyclic aging of the alloys is performed by pre-oxidizing all four alloys between individual coking cycles. It should be noted that DMDS is industrially relevant to suppress the carbon oxides formation, as already stated in section 3.1. The purpose of pre-oxidation between every coking cycle was to evaluate the evolution of the coking rates and surface composition of the materials by aging them further by 12 to 14 hour of oxidation in presence of air.

Under similar cracking conditions as section 3.1, it should be noted that the initial coking rate of the 40/48 CrNi alloy performs better than the rest of the alloys, which can be observed in Figure 7 top and Table 5. The 35/45 CrNi alloy performs slightly better than the $25 / 35 \mathrm{CrNi}$ alloy followed by the Al-containing alloy. The pyrolytic coking rates in Figure 7 bottom and Table 5, has a similar trend as compared to Figure 3 bottom. The surface elemental composition of all alloys can observed in Table 12, which are in line with the experiments performed in 
section 3.1. This indicates that the performed steam/air and/or pretreatment procedures are sufficient to generate a good oxide layer on the surface of the alloy.

Figure S. 17 to Figure S. 20 shows the elemental EDX mapping for all alloys that are preoxidized after every coking-decoking cycle without continuous addition of DMDS during steam cracking and without presulfiding the alloys. The 25/35 CrNi alloys in Figure S. 17 appear to have fractured oxide layers at the surface of the coupon. Whereas the $35 / 40 \mathrm{CrNi}$ and $40 / 48$ CrNi alloys appear to have a continuous oxide layer of 2-3 $\mu \mathrm{m}$ thickness. The Al-containing alloy behaves similarly to the previously discussed experiments in this work.

The SEM images of the materials that are pre-oxidized between every coking-decoking cycle with presulfiding and continuous addition of DMDS during steam cracking of ethane, are shown in Figure 10 and elemental EDX mapping are given in Figure S. 21 to Figure S. 24 respectively. The 25/35 CrNi alloy, Figure S. 21, has high chromium and manganese content and oxide spallation on the surface can be observed. Increased carbon growth on these $25 / 35 \mathrm{CrNi}$ alloys in the presence of DMDS has been previously reported ${ }^{23,25,51}$. Jakobi et al. reported that under increased carbon growth and carburizing conditions chromium oxide to carbide transformations was seen mainly in the intermediate chromium oxide layer until it was completely transformed and that, after one coking-decoking cycle, the surface of the sample was covered by coral-like material consisting of small oxides of chromium or chromium and manganese. It was found that addition of DMDS indirectly intensifies the deterioration of oxide by reducing the Cr-Mnspinel on the outer layer of chromium oxide with concomitant formation of small crystals of $\mathrm{MnO}$ and of $\mathrm{MnS}$ particles that grow with the coke $\mathrm{e}^{39,45}$. The observed oxide spallation leaves the iron and nickel in the matrix exposed to the reducing reaction environment, therefore causing the increase in coking rates which are consistent with the experimental observations in Figure 8. It can be observed from Figure S. 22 and Figure S. 24 that the 35/45 CrNi alloy has a thicker oxide layer by at least $1 \mu \mathrm{m}$ compared to the $40 / 48 \mathrm{CrNi}$ alloy. 
The continuous addition and presulfiding of DMDS with pre-oxidation between every cokingdecoking cycle, Figure 8 , results in a similar overall trend as compared to the experiments labelled as CA+PreS in Table 2. As noted in Table S. 5 and Table S. 6 and in agreement with previous work $^{51}$, there is no influence of cyclic aging on carbon oxide(s) formation, the relative difference between "Blank" and "CA+PreS" compared to "Pre-O all CC - Blank, CA+PreS" experiments remain the same. It should be noted that the catalytic coking rates of the Alcontaining alloy is $17 \%$ lower when pre-oxidized before every coking cycle. A similar trend can also be noticed in pyrolytic coking rates in Figure 8 bottom, where the 40/48 CrNi and Alcontaining alloys show similar coking rates after aging, i.e. in the eight coking cycle. From comparison of Table 11 and Table 13, we can observe that the surface composition of the Alcontaining alloy is slightly increased in aluminum content.

\subsection{Pre-oxidation temperature}

The temperature of the initial pre-oxidation step in Table 1, was increased from $1023 \mathrm{~K}$ to 1223 $\mathrm{K}$ in the presence of air. The increase in temperature is to enable development of the surface alpha-alumina layer on the Al-containing alloy that is fully formed at temperatures of $1223 \mathrm{~K}$ and higher ${ }^{39}$. In comparison to the $\mathrm{CA}+$ PreS labelled experiments, Table 2, the Al-containing alloy outperforms itself significantly when pre-oxidized at $1223 \mathrm{~K}$ by approximately $50 \%$ in terms of coking rates. From Table 6, the overall performance of alloys are similar, except for the Al-containing alloy, which performs marginally better than the 40/48 CrNi alloy after aging, i.e. in its eight coking-decoking cycle. EDX analysis of the Al-cont. sample pre-oxidized at $1223 \mathrm{~K}$ in air for 12 hours, showed that the amount of Fe and $\mathrm{Ni}$ on the surface is reduced by $60 \%$ as compared to previous research ${ }^{19}$, where pre-oxidation was performed at $1023 \mathrm{~K}$. This seems to indicate that increasing the pre-oxidation to $1223 \mathrm{~K}$ further enriches the $\mathrm{Al}$ content at the surface, the formation of a surface $\alpha-\mathrm{A} 12 \mathrm{O} 3$ layer remains incomplete. As reported by $\mathrm{I}$. Levin et al. ${ }^{52}$ and D. Jakobi et al. ${ }^{45}$, a fully developed $\alpha$-Al2O3 layer at the surface requires 
temperatures above $1223 \mathrm{~K}$. Consequently, this makes the Al-containing alloy better in terms of coking rates than the rest of the alloys. There is no influence of the pre-oxidation temperature on carbon oxide(s) formation during steam cracking as long as the coils are presulfided and continuously fed with DMDS during the operation. Similar observations can be made from Table 14, the surface composition of the Al-containing alloy shows an increased aluminum content, compared to Table 11. Both, Fe and Ni content in all four materials are reduced by approximately 10 to 15 percent (Table 14). This is most likely the explanation for the lower coking rates, which are in line with the SEM and EDX observations.

From the supporting information (Figure S. 25 to Figure S. 28) the $25 / 35 \mathrm{CrNi}$ and $35 / 45 \mathrm{CrNi}$ alloys suffer from oxide spallation, leading to higher coking rates, as observed from Figure 9 and Figure 8. The Al-containing alloy (Figure S. 27) displayed a slightly thicker and more homogenous oxide layer in comparison to $\mathrm{CA}+$ PreS labelled experimental conditions (Figure S. 15). The coking rates for the Al-containing alloy in Figure 9 are the lowest compared to all other materials. From Figure S. 28, the 40/48 CrNi oxide layer has a significantly larger chromium and manganese content in the oxide layer at the surface of the coupon.

\section{Conclusions}

Four different super alloys were experimentally evaluated under seven different conditions in terms of anti-coking performance. These results show that coke reduction attributed to sulfur pretreatment or continuous addition, prior/subsequent to cracking, is indeed a myth. Sulfur promotes coke formation, both for $\mathrm{NiCr}$ and $\mathrm{Al}$ containing high temperature alloys, rather than suppressing it. Sulfur addition as pretreatment or continuous addition is primarily beneficial to suppress carbon oxide(s). Overall, the worst performance was observed for the $25 / 35 \mathrm{CrNi}$ alloy. In the absence of DMDS, the Al-containing material had a two to three times higher coking rate than the other non-Al alloys tested. Dosing of the optimal amount of DMDS is thus 
crucial for CrNi alloys. When DMDS was added continuously in the feed, the best performance was observed for the $\mathrm{CrNi}$ alloy with the highest $\mathrm{Cr}$ content, while the worst performance was shown for the $25 / 35 \mathrm{CrNi}$ alloy at initial pre-oxidation temperature at $1023 \mathrm{~K}$. The effect of presulfiding is more pronounced in terms of coking rates when applied on a Blank run than on a CA run. Cyclic aging of the alloys in presence of DMDS has an effect on the CrNi alloys, high chromium and manganese content and oxide spallation for the 25/35 $\mathrm{CrNi}$ and $35 / 45 \mathrm{CrNi}$ alloys were observed. When performing a high-temperature pre-oxidation at $1223 \mathrm{~K}$, the Alcontaining alloy has the most stable behavior in terms of coking, performing better than all CrNi alloys. The CrNi alloys showed a decrease in coke resistance with an increase of the initial pre-oxidation temperature to $1223 \mathrm{~K}$, for which $25 / 35 \mathrm{CrNi}$ and $35 / 45 \mathrm{CrNi}$ alloys showed spallation of the oxide layers. The presence of $\mathrm{Cr}, \mathrm{Mn}$ and $\mathrm{Al}$ on top of the surface is able to improve the anti-coking behavior of an alloy, but their relative anti-coking performance proves to be strongly dependent on the relative amounts of $\mathrm{Cr}-\mathrm{Ni}$ content. According to the results, Alcontaining samples show better resistance to coke formation for ethane cracking. A thin, but uniform, $\alpha-\mathrm{A} 12 \mathrm{O} 3$ layer is formed on top of the surface after exposing to high temperature preoxidation, which is stable and has no observed oxide spallation. Therefore, the Al-containing alloy will only perform better when the initial pre-oxidation temperature is set at least at 1223 $\mathrm{K}$, leading to lower and more stable coking rates. 


\section{Acknowledgements:}

The authors acknowledge the financial support from the European Union H2020 (H2020SPIRE-04-2016) under the agreement number $n^{\circ}$ 723706, from the European Research Council under the European Union's Horizon 2020 research and innovation programme / ERC grant agreement $n^{\circ} 818607$ and the EFRO Interreg V Flanders-Netherlands program under the IMPROVED project.

\section{Nomenclature}
A Atomic mass of element $\left[\mathrm{g} \cdot \mathrm{mol}^{-1}\right]$
DMDS dimethyl disulfide
EDX Energy Dispersive X-ray analysis
FID Flame Ionization Detector
F Flow rate $\left[10^{-6} \mathrm{~kg} \mathrm{~s}^{-1}\right]$
$\mathrm{H} \quad$ Penetration depth $[\mu \mathrm{m}]$
$\mathrm{CC}_{\mathrm{i}} \quad$ Coking-decoking Cycle number, $\mathrm{i}$
JSR Jet-stirred reactor
L Nominal thickness $[\mu \mathrm{m}]$
$\mathrm{m}_{\mathrm{tj}} \quad$ mass of coke at time $\mathrm{j}[\mathrm{kg}]$
MOT maximum operating temperature $[\mathrm{K}]$
Mc amount of coke deposited on the sample [ $\mathrm{g}$ ]
$\mathrm{P}_{\text {tot }} \quad$ reactor pressure $[\mathrm{MPa}]$
$\mathrm{P} / \mathrm{E} \quad$ ratio of propylene [ wt \%] to ethylene [ wt \% ]
$\mathrm{R}_{\alpha} \quad$ mean surface roughness [ $\mu \mathrm{m}$ ]
$r_{c} \quad$ coking rate $\left[\mathrm{kg} \cdot \mathrm{s}^{-1} \cdot \mathrm{m}^{-2}\right]$ 


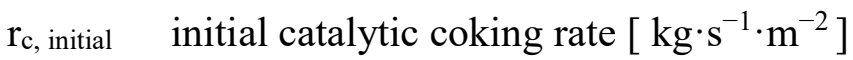

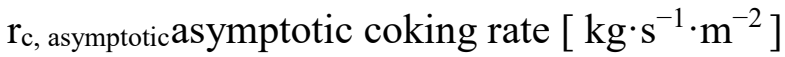

$r_{x-y} \quad$ average coking rate in between the given time intervals $\left[\mathrm{kg} \cdot \mathrm{s}^{-1} \cdot \mathrm{m}^{-2}\right]$

RGA Refinery Gas Analyzer

S Surface area of the coupon $\left[\mathrm{m}^{2}\right]$

SEM Scanning Electron Microscopy

TCD Thermal Conductivity Detector

$\mathrm{T} \quad$ temperature $[\mathrm{K}]$

$\mathrm{V} \quad$ Accelerating voltage $[\mathrm{kV}]$

$\mathrm{z} \quad$ Atomic number

\section{Greek}

\begin{tabular}{ll}
\hline \hline$\delta$ & dilution $\left[\mathrm{kg} \cdot \mathrm{kg}^{-1}\right]$ \\
$\rho$ & Density of the material $\left[\mathrm{g} \cdot \mathrm{cm}^{-3}\right]$ \\
$\tau$ & mean residence time $[\mathrm{s}]$ \\
\hline
\end{tabular}

\section{Supporting Information for Publication}

A short description regarding the SEM and EDX results together with figures and tables that guide the reader through the publication content are given in the supporting information. This information is available free of charge via the Internet on http://pubs.acs.org. 


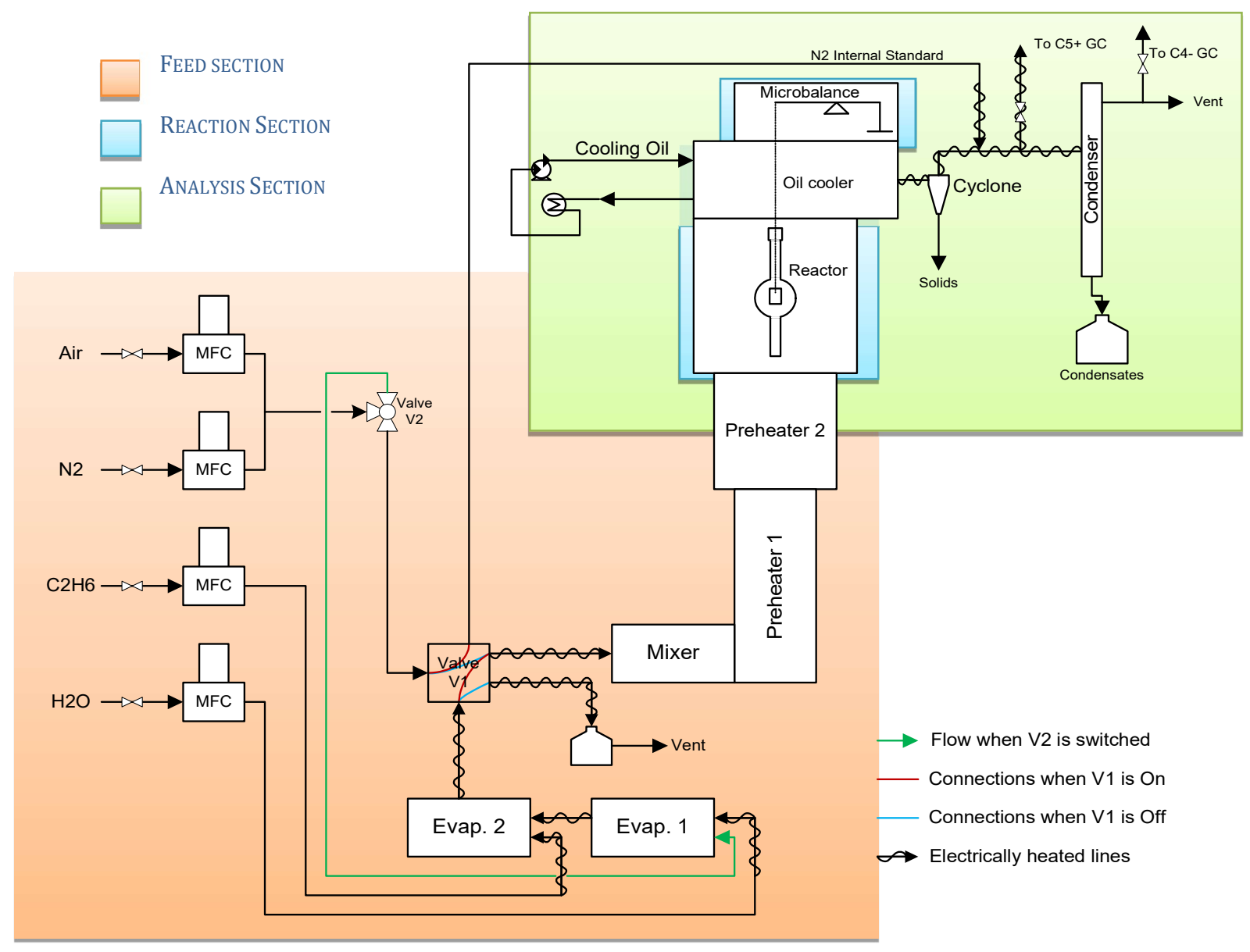

Figure 1: Diagram of the thermogravimetric set-up for the study of coke deposition during steam cracking of ethane. Reprinted with permission from ref. 42. Copyright (2017) American Chemical Society. 


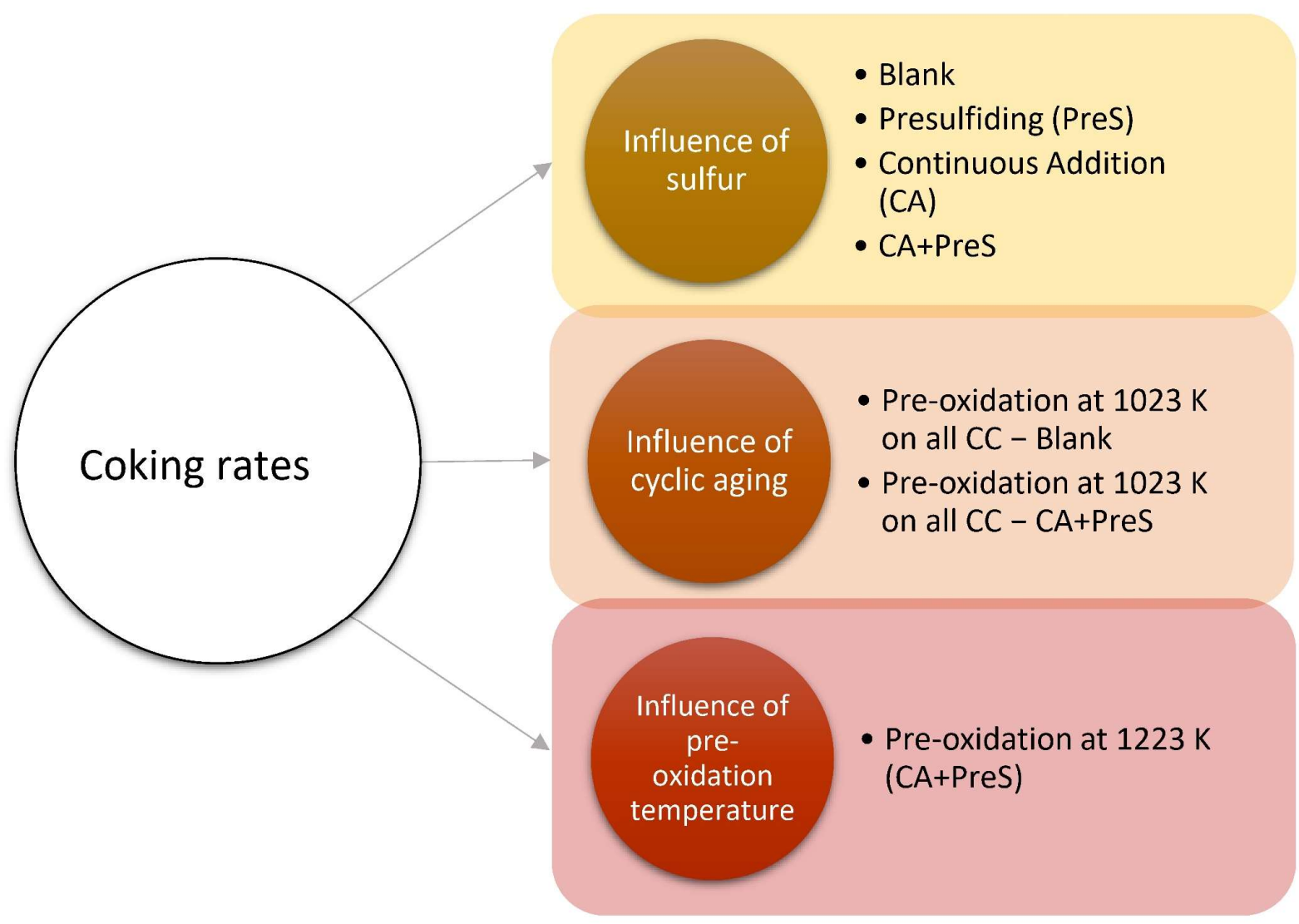

Figure 2 Overview of the variation in experimental conditions during steam cracking of ethane. 


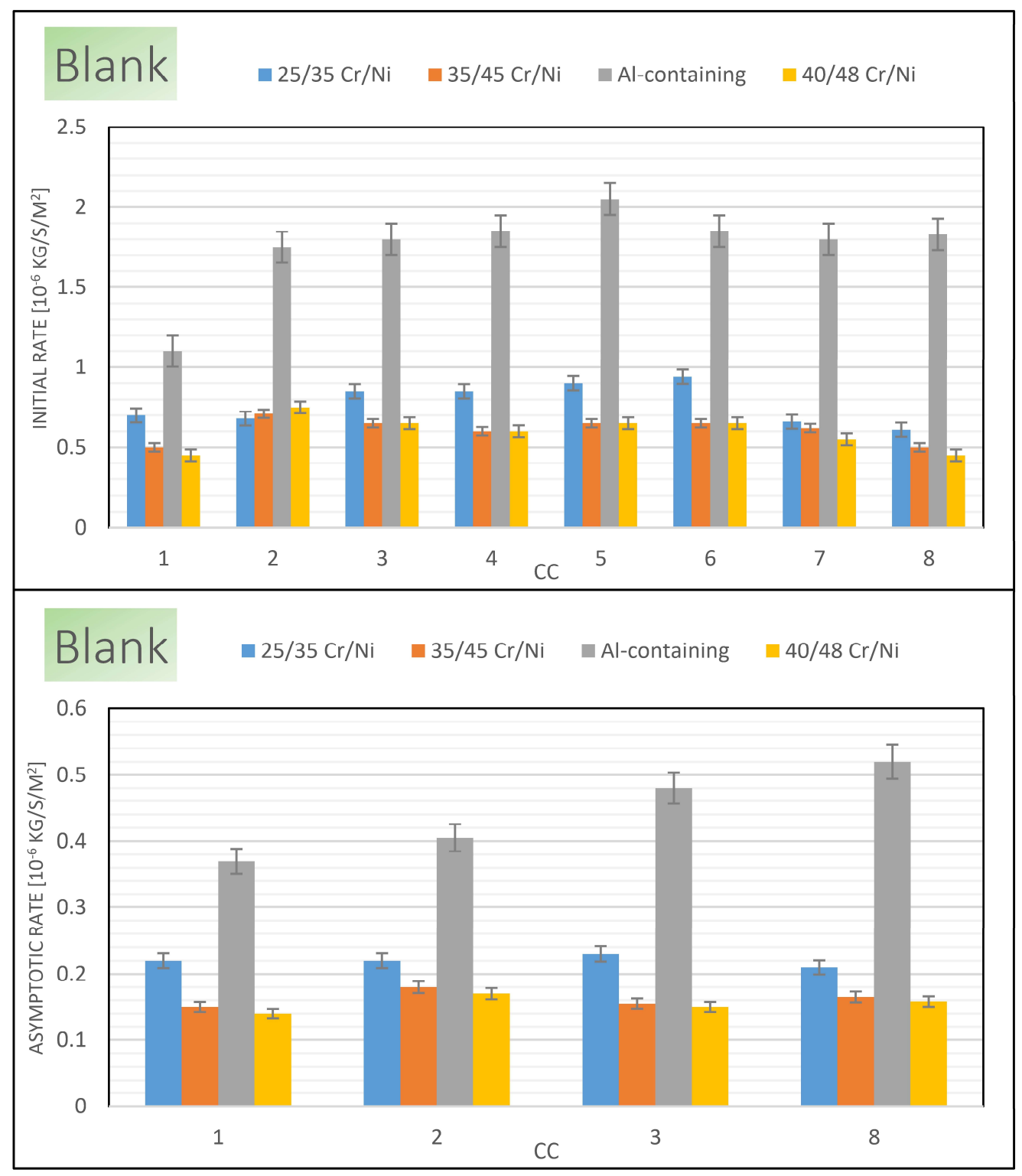

Figure 3: Effect of catalytic (top) and pyrolytic (bottom) coking rates for the blank runs for the four different alloys tested. Ethane steam cracking: $\mathrm{F}_{\mathrm{HC}}=29.18 \times 10^{-6} \mathrm{~kg} \mathrm{~s}^{-1}, \delta=0.33 \mathrm{~kg}_{\mathrm{H} 2 \mathrm{O}}$ $\mathrm{kg}^{-1} \mathrm{HC}, \mathrm{T}_{\text {reactor }}=1173 \mathrm{~K}, \mathrm{P}=101.35 \mathrm{kPa}, \mathrm{F}_{\mathrm{H} 2 \mathrm{O}}=9.72 \times 10^{-6} \mathrm{~kg} \mathrm{~s}^{-1}$. 


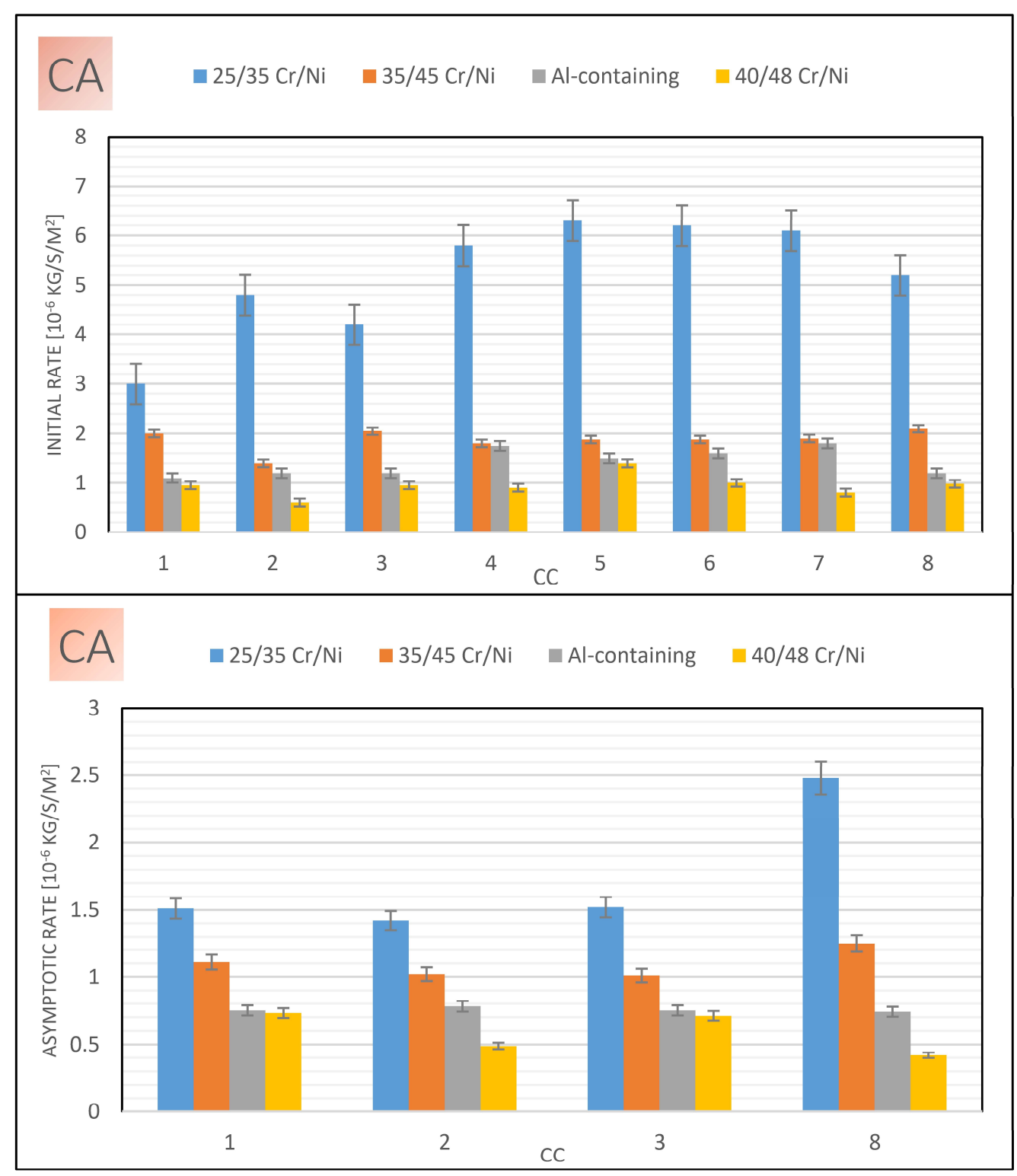

Figure 4: Effect of continuous addition of sulfur on catalytic (top) and pyrolytic (bottom) coking rates for the four different alloys tested. Ethane steam cracking: $\mathrm{F}_{\mathrm{HC}}=29.18 \times 10^{-6} \mathrm{~kg}$ $\mathrm{s}^{-1}, \delta=0.33 \mathrm{~kg}_{\mathrm{H} 2 \mathrm{O} \mathrm{kg}}{ }^{-1} \mathrm{HC}, \mathrm{T}_{\text {reactor }}=1173 \mathrm{~K}, \mathrm{P}=101.35 \mathrm{kPa}, \mathrm{F}_{\mathrm{H} 2 \mathrm{O}}=9.72 \times 10^{-6} \mathrm{~kg} \mathrm{~s}^{-1}$. 


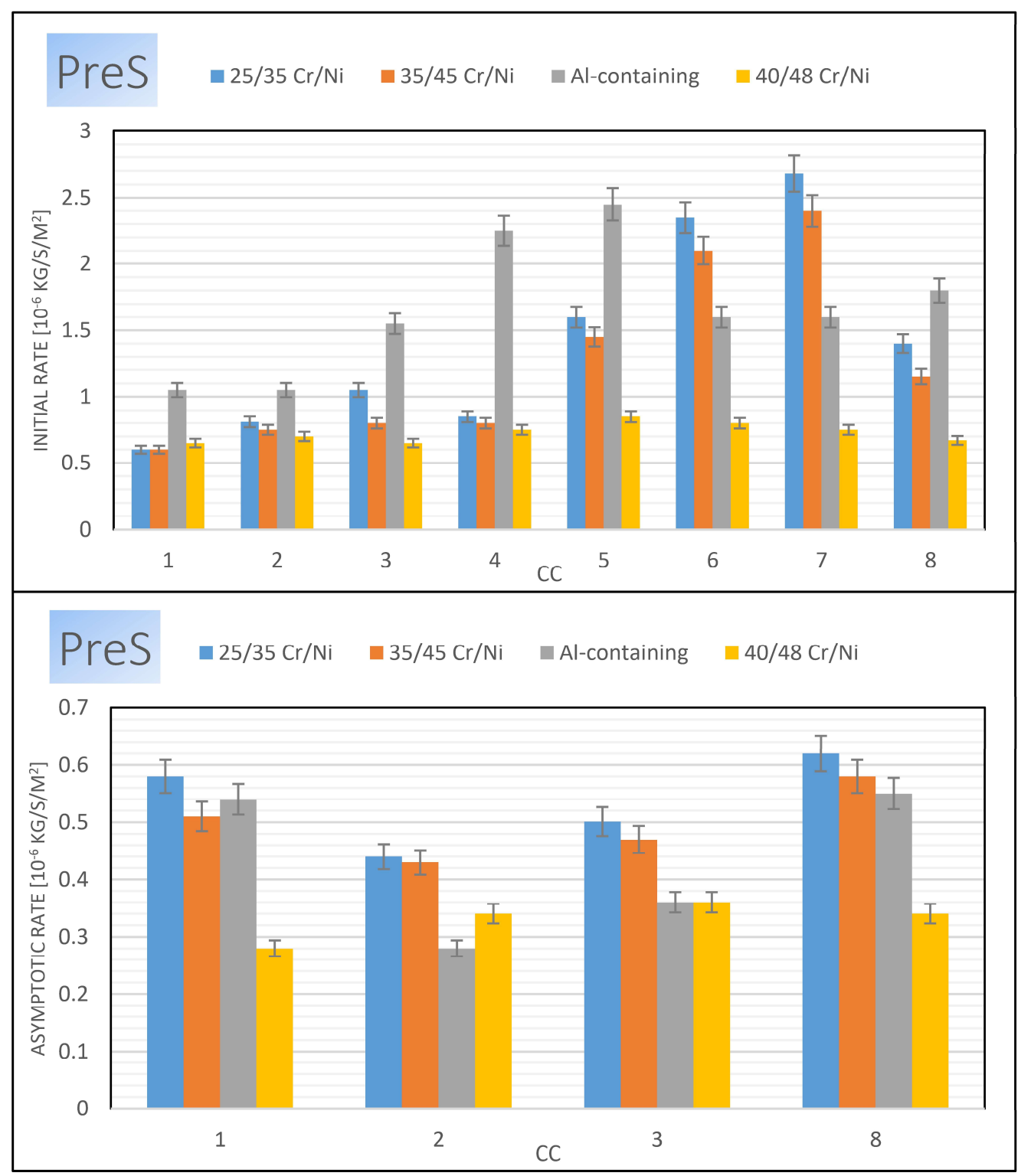

Figure 5: Effect of presulfiding on catalytic (top) and pyrolytic (bottom) coking rates for the four different alloys tested. Ethane steam cracking: $\mathrm{F}_{\mathrm{HC}}=29.18 \times 10^{-6} \mathrm{~kg} \mathrm{~s}^{-1}, \delta=0.33 \mathrm{~kg}_{\mathrm{H} 2 \mathrm{O} \mathrm{kg}}$ ${ }_{\mathrm{HC}}, \mathrm{T}_{\text {reactor }}=1173 \mathrm{~K}, \mathrm{P}=101.35 \mathrm{kPa}, \mathrm{F}_{\mathrm{H} 2 \mathrm{O}}=9.72 \times 10^{-6} \mathrm{~kg} \mathrm{~s}^{-1}$. 


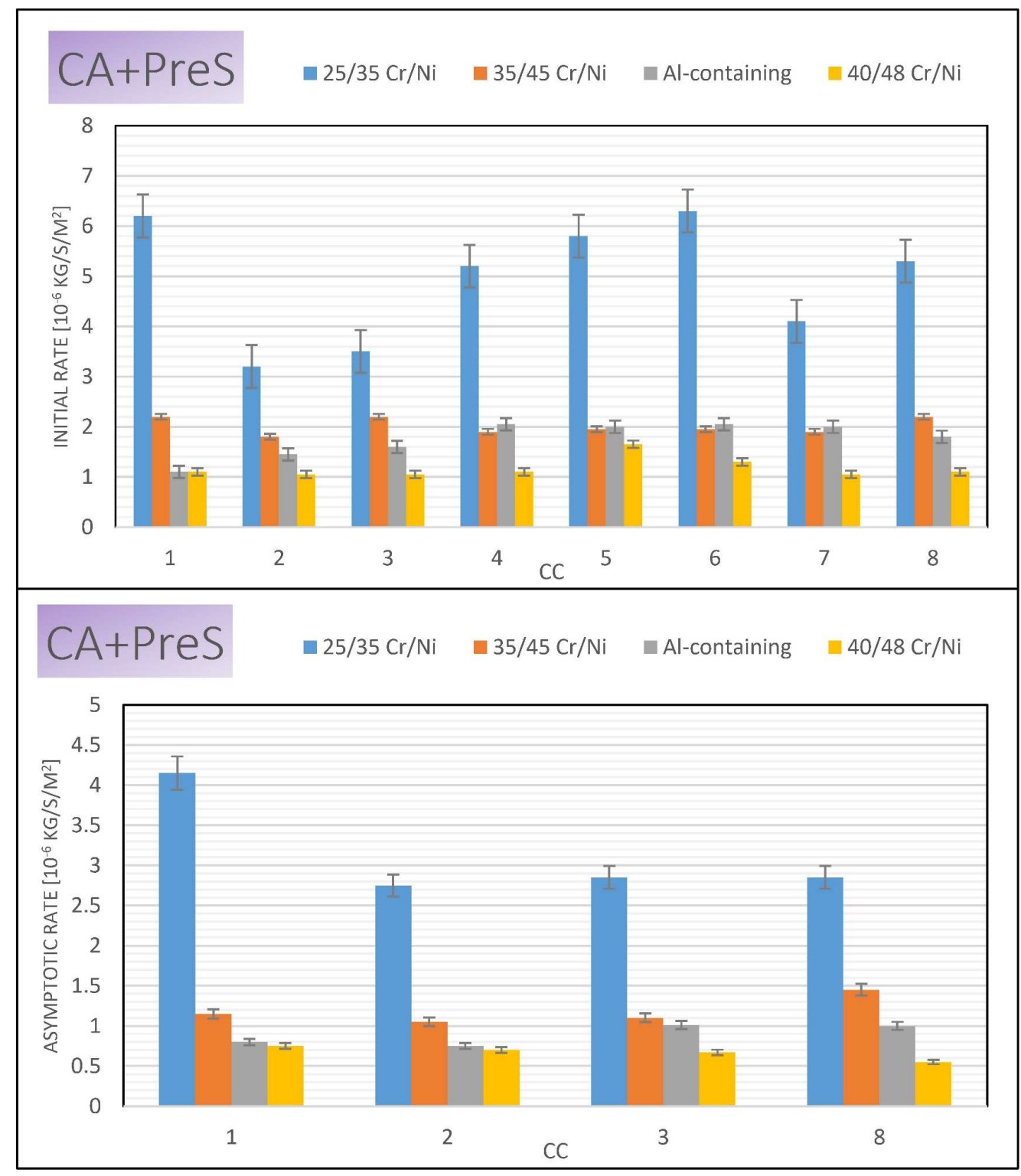

Figure 6: Effect of continuous addition and presulfiding of sulfur on catalytic (top) and pyrolytic (bottom) coking rates for the four different alloys tested. Ethane steam cracking:

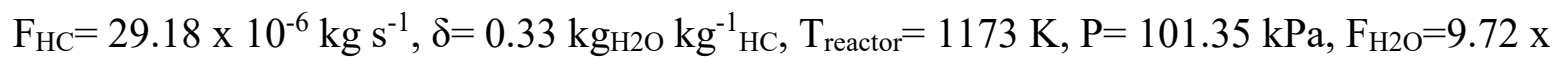
$10^{-6} \mathrm{~kg} \mathrm{~s}^{-1}$. 


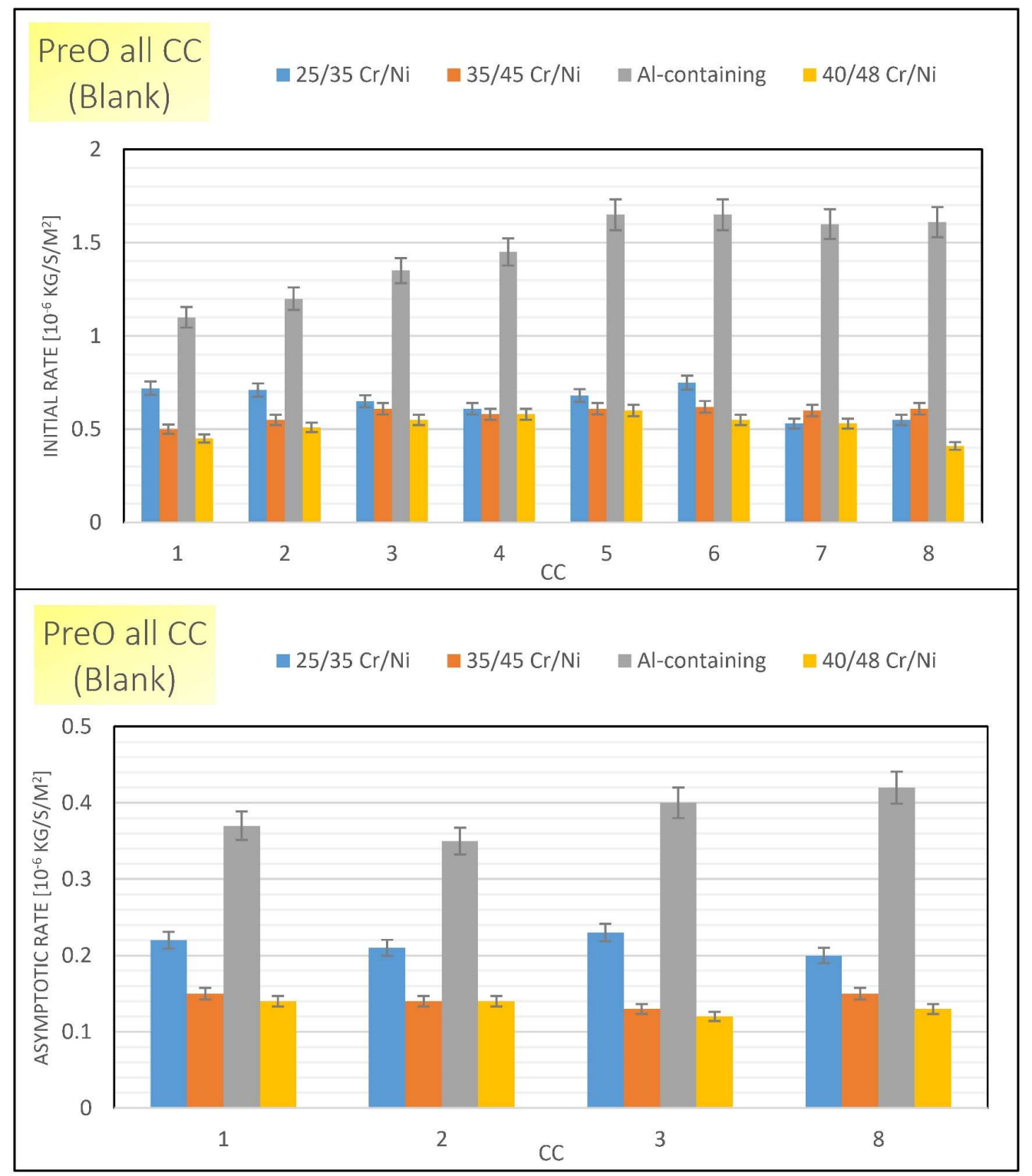

Figure 7: Effect of pre-oxidation on all coking-cycles with blank runs on catalytic (top) and pyrolytic (bottom) coking rates for the four different alloys tested. Ethane steam cracking:

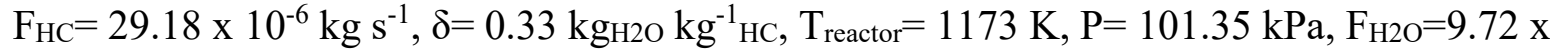
$10^{-6} \mathrm{~kg} \mathrm{~s}^{-1}$. 


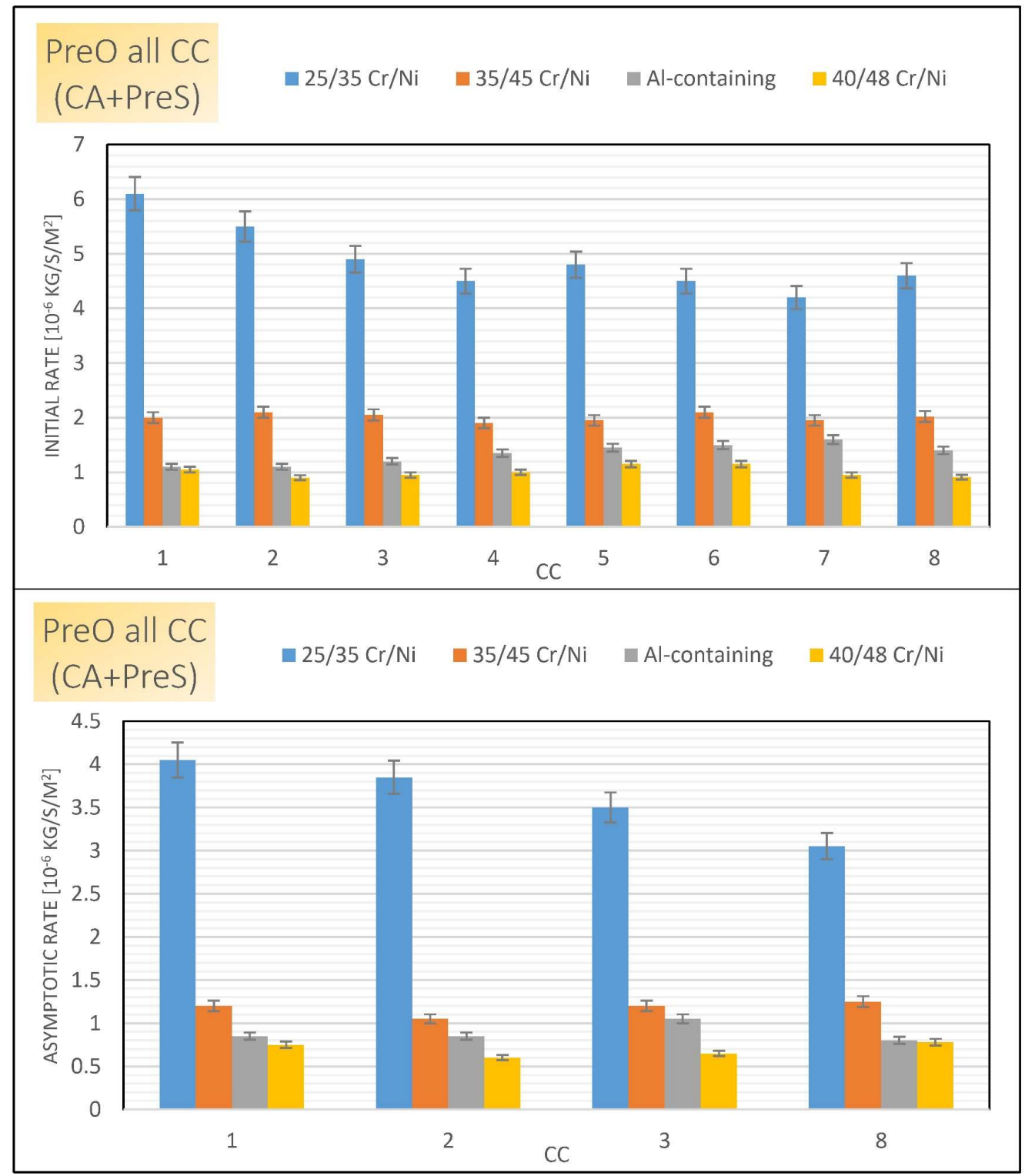

Figure 8: Effect of pre-oxidation on all coking-cycles with continuous addition and presulfiding on catalytic (top) and pyrolytic (bottom) coking rates for the four different alloys tested. Ethane steam cracking: $\mathrm{F}_{\mathrm{HC}}=29.18 \times 10^{-6} \mathrm{~kg} \mathrm{~s}^{-1}, \delta=0.33 \mathrm{~kg}_{\mathrm{H} 2 \mathrm{O} \mathrm{kg}^{-1} \mathrm{HC}}, \mathrm{T}_{\text {reactor }}=1173 \mathrm{~K}$,

$$
\mathrm{P}=101.35 \mathrm{kPa}, \mathrm{F}_{\mathrm{H} 2 \mathrm{O}}=9.72 \times 10^{-6} \mathrm{~kg} \mathrm{~s}^{-1} \text {. }
$$




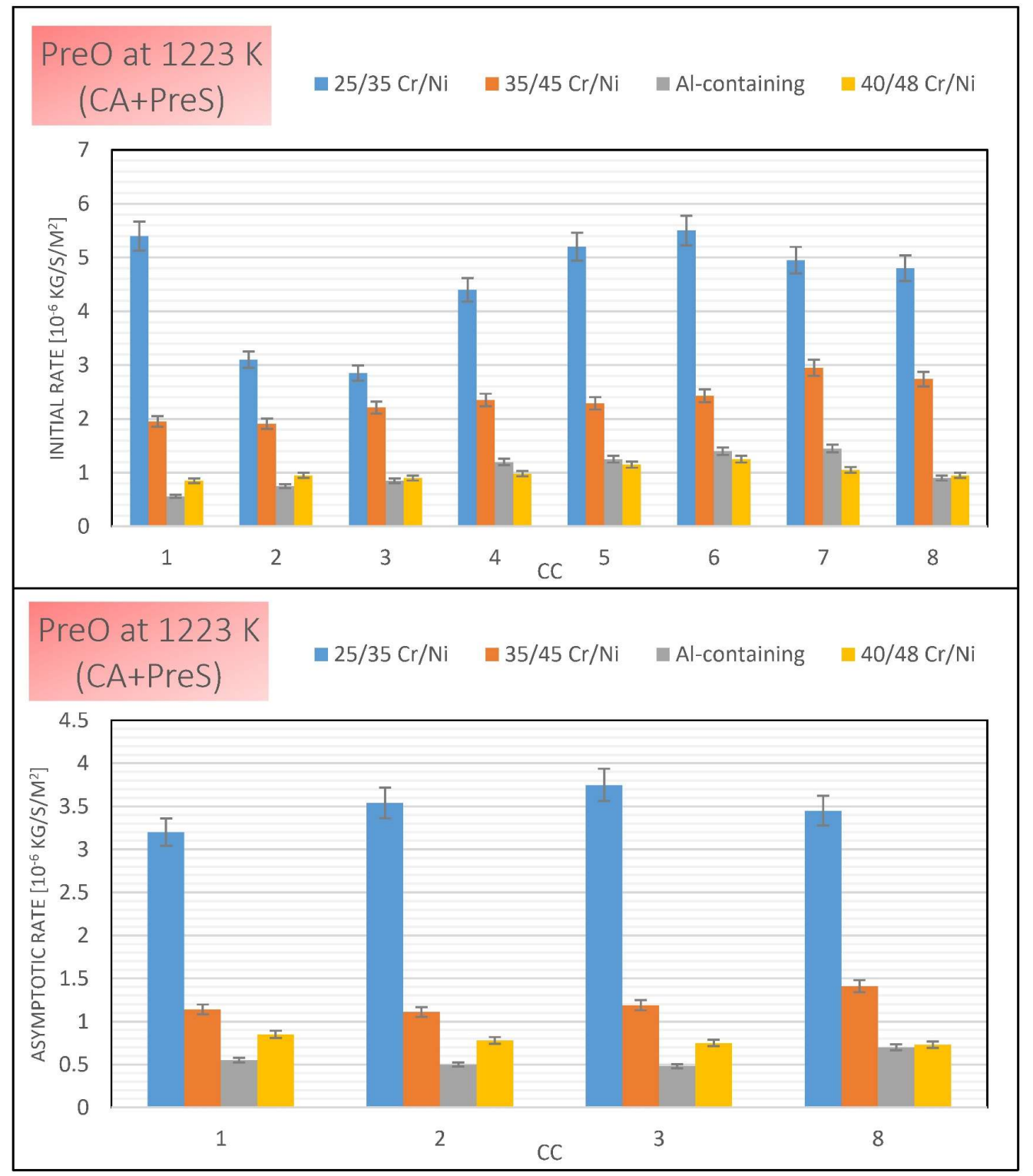

Figure 9: Effect of initial pre-oxidation temperature at $1223 \mathrm{~K}$ on catalytic (top) and pyrolytic (bottom) coking rates for the four different alloys tested. Ethane steam cracking: $F_{H C}=29.18 \mathrm{x}$

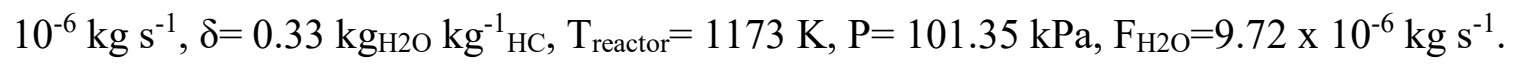



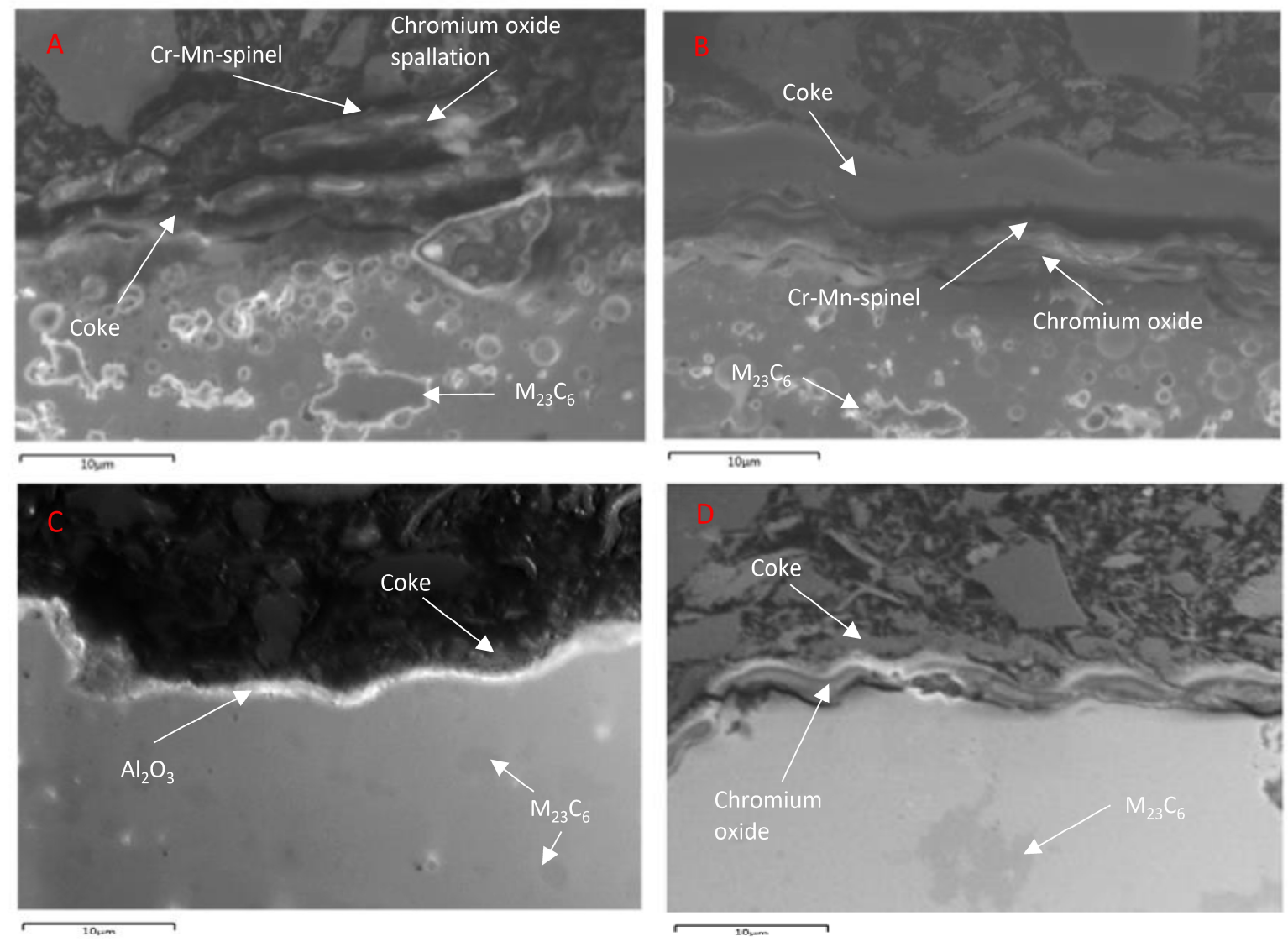

Figure 10: Scanning electron microscopy images of the coked coupons after pre-oxidizing between individual coking-decoking cycles with presulfiding and continuous addition of sulfur; (A) 25/35 CrNi (B) 35/45 CrNi (C) Al-cont. (D) 40/48 CrNi. All the images are captured with accelerating voltage of $12 \mathrm{kV}$. 
Table 1: Operational procedures and conditions during pretreatment, decoking and cracking

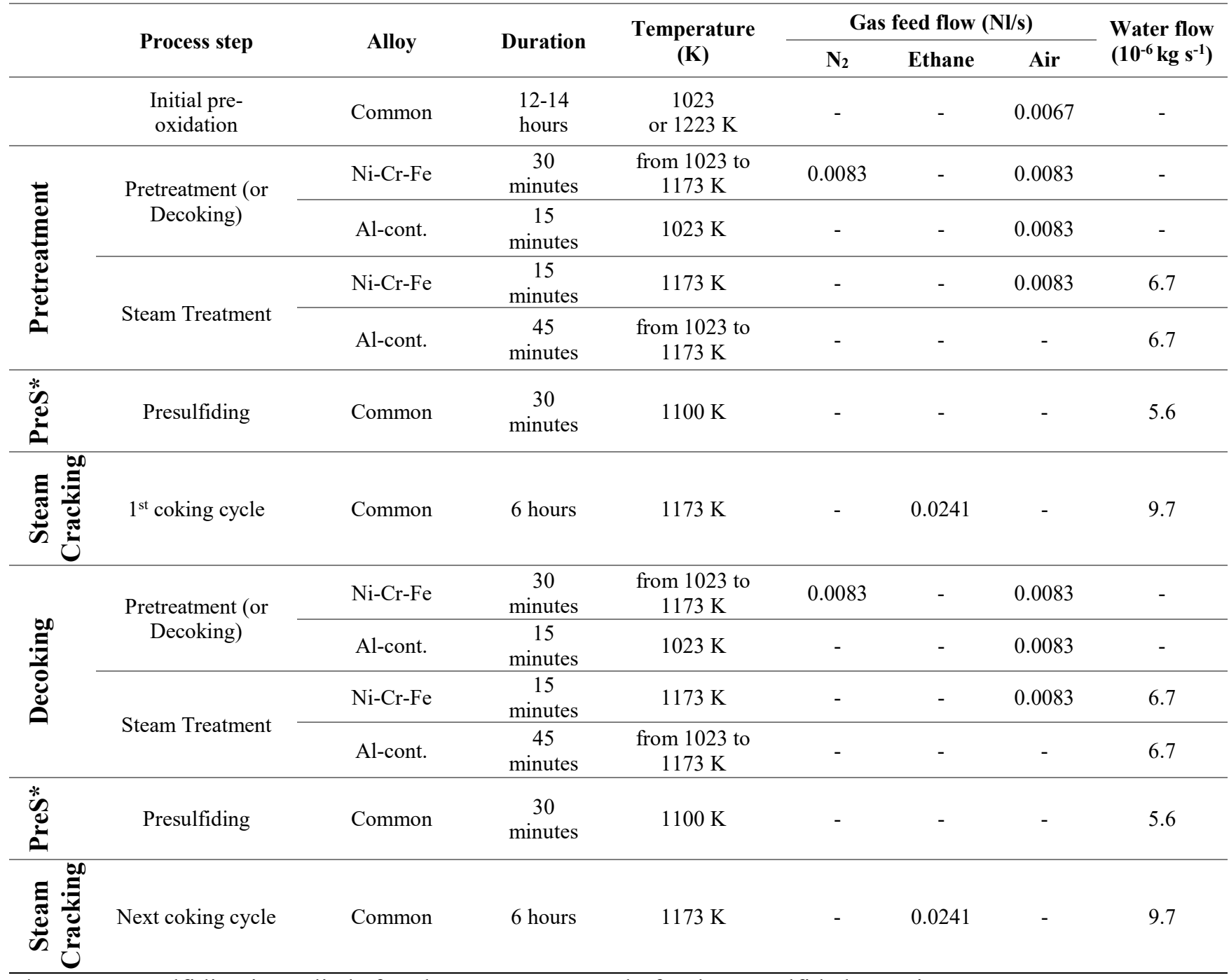

* PreS : presulfiding is applied after the pretreatment only for the presulfided experiments 
Table 2: Summary of experimental labels based on the conditions

\begin{tabular}{cc}
\hline Label & Experimental conditions \\
\hline Blank & $\begin{array}{c}\text { No addition of DMDS before or during } \\
\text { cracking }\end{array}$ \\
\hline PreS & Presulfiding is performed before cracking \\
CA + PreS & $\begin{array}{c}\text { DMDS is added continuously diluted in the } \\
\text { water }\end{array}$ \\
PreO all CC (Blank) & $\begin{array}{c}\text { A presulfiding step is performed, while } \\
\text { DMDS is also fed during cracking }\end{array}$ \\
PreO all CC (CA + PreS) & $\begin{array}{c}\text { Pre-oxidation is performed before all the } \\
\text { coking cycles without sulfur before or } \\
\text { during cracking }\end{array}$ \\
& $\begin{array}{c}\text { Pre-oxidation is performed before all the } \\
\text { coking cycles, followed by CA }+ \text { PreS step } \\
\text { Pre-oxidation is performed once at 1223 K } \\
\text { before first coking cycle, followed by CA }+ \\
\text { PreS step }\end{array}$ \\
\hline \hline
\end{tabular}


Table 3: Catalytic and asymptotic coking rates during the blank and presulfiding (PreS) runs for the four different alloys tested

\section{Blank}

Experiment

25/35 CrNi 35/45 CrNi 40/48 CrNi Al-containing

\begin{tabular}{|c|c|c|c|c|c|}
\hline \multirow{9}{*}{ 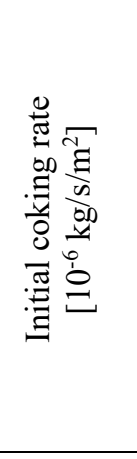 } & cc & & & & \\
\hline & 1 & 0.71 & 0.50 & 0.44 & 1.04 \\
\hline & 2 & 0.67 & 0.79 & 0.74 & 1.77 \\
\hline & 3 & 0.86 & 0.62 & 0.58 & 1.87 \\
\hline & 4 & 0.85 & 0.55 & 0.54 & 1.93 \\
\hline & 5 & 0.96 & 0.64 & 0.62 & 2.02 \\
\hline & 6 & 0.97 & 0.66 & 0.64 & 1.90 \\
\hline & 7 & 0.67 & 0.57 & 0.55 & 1.79 \\
\hline & 8 & 0.63 & 0.50 & 0.46 & 1.82 \\
\hline \multirow{5}{*}{ 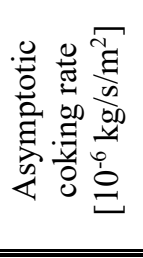 } & cc & & & & \\
\hline & 1 & 0.22 & 0.15 & 0.14 & 0.38 \\
\hline & 2 & 0.22 & 0.17 & 0.17 & 0.41 \\
\hline & 3 & 0.23 & 0.15 & 0.14 & 0.47 \\
\hline & 8 & 0.21 & 0.16 & 0.15 & 0.52 \\
\hline & & \multicolumn{4}{|c|}{ PreS } \\
\hline \multirow{9}{*}{ 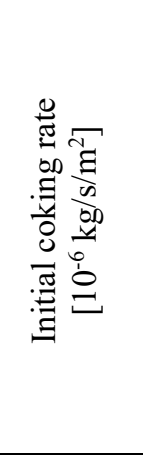 } & cc & & & & \\
\hline & 1 & 0.63 & 0.65 & 0.67 & 1.04 \\
\hline & 2 & 0.87 & 0.85 & 0.82 & 1.06 \\
\hline & 3 & 1.04 & 1.06 & 0.68 & 1.53 \\
\hline & 4 & 0.91 & 0.81 & 0.81 & 2.19 \\
\hline & 5 & 1.68 & 1.46 & 0.91 & 2.48 \\
\hline & 6 & 2.34 & 1.64 & 0.87 & 1.62 \\
\hline & 7 & 2.71 & 1.71 & 0.71 & 1.61 \\
\hline & 8 & 1.36 & 1.26 & 0.68 & 1.83 \\
\hline \multirow{5}{*}{ 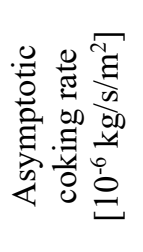 } & cc & & & & \\
\hline & 1 & 0.57 & 0.54 & 0.28 & 0.55 \\
\hline & 2 & 0.45 & 0.42 & 0.35 & 0.29 \\
\hline & 3 & 0.51 & 0.49 & 0.36 & 0.37 \\
\hline & 8 & 0.63 & 0.53 & 0.34 & 0.56 \\
\hline
\end{tabular}


Table 4: Catalytic and asymptotic coking rates during the continuous addition of sulfur (CA) and presulfiding with continuous addition $(\mathrm{CA}+\mathrm{PreS})$ experiments

\begin{tabular}{|c|c|c|c|c|c|}
\hline \multirow[b]{2}{*}{ Experiment } & & \multicolumn{4}{|c|}{$\mathbf{C A}$} \\
\hline & & 25/35 CrNi & 35/45 CrNi & 40/48 CrNi & Al-containing \\
\hline \multirow{9}{*}{ 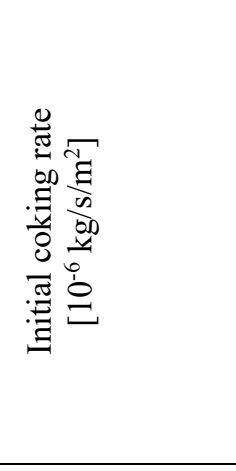 } & cc & & & & \\
\hline & 1 & 3.03 & 2.07 & 0.94 & 1.13 \\
\hline & 2 & 4.74 & 1.44 & 0.60 & 1.28 \\
\hline & 3 & 4.23 & 2.11 & 0.92 & 1.26 \\
\hline & 4 & 5.85 & 1.78 & 0.91 & 1.64 \\
\hline & 5 & 6.45 & 1.83 & 1.39 & 1.55 \\
\hline & 6 & 6.42 & 1.80 & 0.96 & 1.58 \\
\hline & 7 & 6.39 & 1.77 & 0.84 & 1.64 \\
\hline & 8 & 5.29 & 2.20 & 0.99 & 1.24 \\
\hline \multirow{5}{*}{ 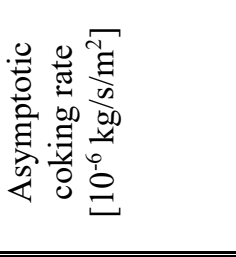 } & cc & & & & \\
\hline & 1 & 1.53 & 1.11 & 0.72 & 0.74 \\
\hline & 2 & 1.43 & 1.00 & 0.48 & 0.75 \\
\hline & 3 & 1.61 & 1.02 & 0.67 & 0.79 \\
\hline & 8 & 2.47 & 1.23 & 0.40 & 0.79 \\
\hline Experiment & & \multicolumn{4}{|c|}{$\overline{c \text { CA + PreS }}$} \\
\hline \multirow{9}{*}{ 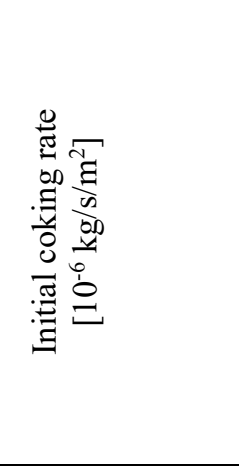 } & ce & & & & \\
\hline & 1 & 6.28 & 2.32 & 1.08 & 1.19 \\
\hline & 2 & 3.39 & 1.61 & 1.05 & 1.42 \\
\hline & 3 & 3.63 & 2.36 & 1.06 & 1.60 \\
\hline & 4 & 5.28 & 1.87 & 1.11 & 2.04 \\
\hline & 5 & 5.78 & 1.92 & 1.62 & 1.96 \\
\hline & 6 & 6.43 & 1.89 & 1.26 & 2.10 \\
\hline & 7 & 4.12 & 1.86 & 1.06 & 1.96 \\
\hline & 8 & 5.42 & 2.31 & 1.10 & 1.72 \\
\hline \multirow{5}{*}{ 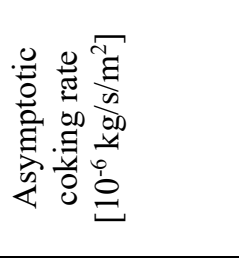 } & cc & & & & \\
\hline & 1 & 4.17 & 1.15 & 0.80 & 0.87 \\
\hline & 2 & 2.79 & 1.06 & 0.72 & 0.86 \\
\hline & 3 & 2.91 & 1.10 & 0.72 & 1.06 \\
\hline & 8 & 2.89 & 1.38 & 0.53 & 1.02 \\
\hline
\end{tabular}


Table 5: Catalytic and asymptotic coking rates during pre-oxidation between the coking cycles (Pre-O all CC) on blank and presulfiding with continuous addition (CA+PreS) experiments

\begin{tabular}{|c|c|c|c|c|c|}
\hline \multirow[b]{2}{*}{ Experiment } & & \multicolumn{4}{|c|}{ Pre-O all CC - Blank } \\
\hline & & 25/35 CrNi & 35/45 CrNi & 40/48 CrNi & Al-containing \\
\hline \multirow{9}{*}{ 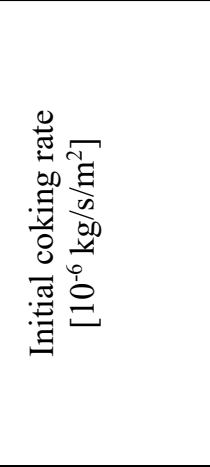 } & cc & & & & \\
\hline & 1 & 0.72 & 0.51 & 0.45 & 1.10 \\
\hline & 2 & 0.71 & 0.55 & 0.51 & 1.20 \\
\hline & 3 & 0.65 & 0.61 & 0.55 & 1.35 \\
\hline & 4 & 0.61 & 0.58 & 0.58 & 1.45 \\
\hline & 5 & 0.68 & 0.61 & 0.60 & 1.65 \\
\hline & 6 & 0.75 & 0.62 & 0.55 & 1.65 \\
\hline & 7 & 0.53 & 0.60 & 0.53 & 1.59 \\
\hline & 8 & 0.55 & 0.61 & 0.41 & 1.61 \\
\hline \multirow{5}{*}{ 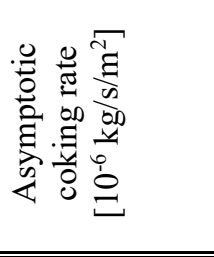 } & cc & & & & \\
\hline & 1 & 0.22 & 0.15 & 0.14 & 0.37 \\
\hline & 2 & 0.21 & 0.14 & 0.14 & 0.35 \\
\hline & 3 & 0.23 & 0.13 & 0.12 & 0.41 \\
\hline & 8 & 0.21 & 0.15 & 0.13 & 0.42 \\
\hline Experiment & & \multicolumn{4}{|c|}{ Pre-O all CC - PreS + CA } \\
\hline \multirow{9}{*}{ 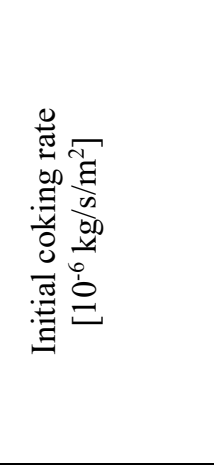 } & cc & & & & \\
\hline & 1 & 6.10 & 2.01 & 1.05 & 1.10 \\
\hline & 2 & 5.50 & 2.10 & 0.90 & 1.10 \\
\hline & 3 & 4.91 & 2.05 & 0.95 & 1.19 \\
\hline & 4 & 4.50 & 1.90 & 1.00 & 1.35 \\
\hline & 5 & 4.82 & 1.95 & 1.15 & 1.45 \\
\hline & 6 & 4.50 & 2.10 & 1.15 & 1.49 \\
\hline & 7 & 4.18 & 1.95 & 0.95 & 1.60 \\
\hline & 8 & 4.59 & 2.02 & 0.91 & 1.38 \\
\hline \multirow{5}{*}{ 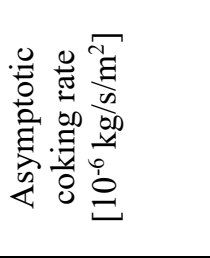 } & cc & & & & \\
\hline & 1 & 4.05 & 1.21 & 0.75 & 0.85 \\
\hline & 2 & 3.85 & 1.05 & 0.60 & 0.85 \\
\hline & 3 & 3.50 & 1.20 & 0.65 & 1.05 \\
\hline & 8 & 3.05 & 1.25 & 0.78 & 0.81 \\
\hline
\end{tabular}


Table 6: Catalytic and asymptotic coking rates after high temperature per-oxidation at $1223 \mathrm{~K}$ with presulfiding and continuous addition experiments

\begin{tabular}{|c|c|c|c|c|c|}
\hline \multirow[t]{2}{*}{ Experiment } & & \multicolumn{4}{|c|}{ PreO at $1223 \mathrm{~K}-\mathrm{PreS}+\mathrm{CA}$} \\
\hline & & 25/35 CrNi & 35/45 CrNi & $40 / 48 \mathrm{CrNi}$ & Al-containing \\
\hline \multirow{9}{*}{ 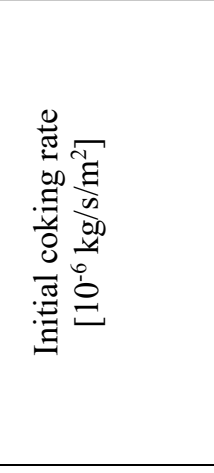 } & cc & & & & \\
\hline & 1 & 5.40 & 1.95 & 0.85 & 0.56 \\
\hline & 2 & 3.10 & 1.91 & 0.95 & 0.75 \\
\hline & 3 & 2.85 & 2.21 & 0.90 & 0.85 \\
\hline & 4 & 4.40 & 2.35 & 0.98 & 1.20 \\
\hline & 5 & 5.20 & 2.29 & 1.15 & 1.25 \\
\hline & 6 & 5.50 & 2.43 & 1.25 & 1.40 \\
\hline & 7 & 4.95 & 2.95 & 1.05 & 1.45 \\
\hline & 8 & 4.80 & 2.74 & 0.95 & 0.90 \\
\hline \multirow{5}{*}{ 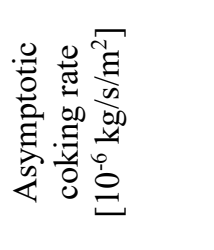 } & cc & & & & \\
\hline & 1 & 3.20 & 1.14 & 0.85 & 0.55 \\
\hline & 2 & 3.54 & 1.11 & 0.78 & 0.50 \\
\hline & 3 & 3.75 & 1.19 & 0.75 & 0.48 \\
\hline & 8 & 3.45 & 1.41 & 0.73 & 0.70 \\
\hline
\end{tabular}


Table 7. Elemental composition of fresh coupons determined by SEM with EDX.

\begin{tabular}{|c|c|c|c|c|}
\hline Material & $25 / 35 \mathrm{CrNi}$ & $35 / 45 \mathrm{CrNi}$ & Al-containing & $40 / 48 \mathrm{CrNi}$ \\
\hline Elements & \multicolumn{4}{|c|}{ [ wt \% ] } \\
\hline $\mathrm{Fe}$ & 37 & 17 & 23 & 9 \\
\hline $\mathrm{Ni}$ & 35 & 45 & 45 & 48 \\
\hline $\mathrm{Cr}$ & 25 & 35 & 25 & 40 \\
\hline Al & - & & 4 & - \\
\hline $\mathrm{Nb}, \mathrm{Mn}, \mathrm{Ti}$ & add & add & add & add \\
\hline
\end{tabular}

Table 8: Top surface elemental composition of the coked samples for the Blank runs with accelerating Voltages of $20 \mathrm{kV}$.

\begin{tabular}{ccccc}
\hline $\begin{array}{c}\text { Blank run } \\
\text { Elements }\end{array}$ & $\begin{array}{c}\mathbf{2 5 / 3 5} \\
\mathbf{C r N i}\end{array}$ & $\begin{array}{c}\mathbf{3 5} / \mathbf{4 5} \\
\mathbf{C r N i} \\
\text { coked samples (wt \%) }\end{array}$ & $\begin{array}{c}\text { Al- } \\
\text { containing }\end{array}$ & $\begin{array}{c}\mathbf{4 0 / 4 8} \\
\mathbf{C r N i}\end{array}$ \\
\hline \hline $\mathrm{Ni}$ & 3.6 & 1.7 & 16.4 & 2.3 \\
$\mathrm{Fe}$ & 4.5 & 1.9 & 9.7 & 0.6 \\
$\mathrm{Cr}$ & 77.5 & 64 & 20.6 & 80.9 \\
\hline $\mathrm{Si}$ & 0.5 & 1.3 & 2 & 1 \\
\hline $\mathrm{Mn}$ & 13.3 & 30.5 & - & 14.8 \\
\hline $\mathrm{Nb}$ & 0.5 & 0.5 & 1 & 0.4 \\
\hline $\mathrm{Al}$ & - & - & 50.3 & - \\
\hline
\end{tabular}

Table 9: Top surface elemental composition of the coked samples for the CA runs. With accelerating Voltage of $20 \mathrm{kV}$.

\begin{tabular}{ccccc}
\hline CA & $\begin{array}{c}\mathbf{2 5 / 3 5} \\
\text { CrNi }\end{array}$ & $\begin{array}{c}\mathbf{3 5} / \mathbf{4 5} \\
\text { CrNi } \\
\text { coked samples (wt \%) }\end{array}$ & $\begin{array}{c}\text { Al- } \\
\text { containing }\end{array}$ & $\begin{array}{c}\mathbf{4 0} / \mathbf{4 8} \\
\mathbf{C r N i}\end{array}$ \\
\hline \hline $\mathrm{Ni}$ & 10.3 & 2.1 & 20.2 & 2.3 \\
\hline $\mathrm{Fe}$ & 9.1 & 2.6 & 11.2 & 0.6 \\
$\mathrm{Cr}$ & 62.1 & 63 & 18.9 & 80.9 \\
\hline $\mathrm{Si}$ & 2.1 & 1.3 & 1.2 & 1 \\
$\mathrm{Mn}$ & 15.5 & 30.7 & - & 15.2 \\
\hline $\mathrm{Nb}$ & 0.9 & - & 0.4 & 0.4 \\
\hline $\mathrm{Al}$ & - & - & 48 & - \\
\hline
\end{tabular}


Table 10: Top surface elemental composition of the coked samples for the PreS runs with accelerating Voltage of $20 \mathrm{kV}$.

\begin{tabular}{ccccc}
\hline PreS & $\begin{array}{c}\mathbf{2 5 / 3 5} \\
\text { CrNi }\end{array}$ & $\begin{array}{c}\mathbf{3 5} / \mathbf{4 5} \\
\text { CrNi } \\
\text { coked samples (wt \%) }\end{array}$ & $\begin{array}{c}\text { Al- } \\
\text { containing }\end{array}$ & $\begin{array}{c}\mathbf{4 0 / 4 8} \\
\text { CrNi }\end{array}$ \\
\hline \hline Elements & 16.2 & 13 & 10 & 10.2 \\
\hline $\mathrm{Ni}$ & 15.7 & 15.5 & 9.6 & 2.3 \\
$\mathrm{Fe}$ & 51.5 & 60.5 & 13.9 & 62.9 \\
\hline $\mathrm{Cr}$ & 4.1 & 1.5 & 5.5 & 2.3 \\
\hline $\mathrm{Si}$ & 11.3 & 8.7 & 3.6 & 19.6 \\
\hline $\mathrm{Mn}$ & 1.2 & 0.8 & 3.1 & 2.8 \\
\hline $\mathrm{Nb}$ & - & - & 54.4 & - \\
\hline $\mathrm{Al}$ & & & & \\
\hline
\end{tabular}

Table 11: Top surface elemental composition of the coked samples for the CA + PreS runs with accelerating Voltage of $20 \mathrm{kV}$.

\begin{tabular}{ccccc}
\hline $\begin{array}{c}\text { CA + PreS } \\
\text { Elements }\end{array}$ & $\begin{array}{c}\mathbf{2 5 / 3 5} \\
\mathbf{C r N i}\end{array}$ & $\begin{array}{c}\mathbf{3 5} / \mathbf{4 5} \\
\mathbf{C r N i} \\
\text { coked samples (wt \%) }\end{array}$ & $\begin{array}{c}\text { Al- } \\
\text { containing }\end{array}$ & $\begin{array}{c}\mathbf{4 0} / \mathbf{4 8} \\
\mathbf{C r N i}\end{array}$ \\
\hline $\mathrm{Ni}$ & 21.7 & 13.1 & 10.1 & 10.6 \\
\hline $\mathrm{Fe}$ & 24.1 & 15.4 & 9.6 & 2.3 \\
\hline $\mathrm{Cr}$ & 40 & 60.3 & 13.7 & 62.5 \\
\hline $\mathrm{Si}$ & 4.1 & 1.4 & 5.9 & 2.5 \\
\hline $\mathrm{Mn}$ & 9.1 & 9 & 3.2 & 19.4 \\
\hline $\mathrm{Nb}$ & 1 & 0.8 & 3.5 & 2.7 \\
\hline $\mathrm{Al}$ & - & - & 54 & - \\
\hline
\end{tabular}

Table 12: Top surface elemental composition of the coked samples for the PreO all CC (Blank) runs with accelerating Voltage of $20 \mathrm{kV}$.

\begin{tabular}{ccccc}
\hline $\begin{array}{c}\text { PreO all CC (Blank) } \\
\text { Elements }\end{array}$ & $\begin{array}{c}\mathbf{2 5 / 3 5} \\
\text { CrNi }\end{array}$ & $\begin{array}{c}\mathbf{3 5 / 4 5} \\
\text { CrNi } \\
\text { coked samples (wt \%) }\end{array}$ & $\begin{array}{c}\text { Al- } \\
\text { containing }\end{array}$ & $\begin{array}{c}\mathbf{4 0 / 4 8} \\
\text { CrNi }\end{array}$ \\
\hline \hline $\mathrm{Ni}$ & 3.5 & 1.95 & 12.5 & 2.12 \\
$\mathrm{Fe}$ & 3.78 & 1.81 & 8.23 & 0.48 \\
$\mathrm{Cr}$ & 79.8 & 65.75 & 23.5 & 80.36 \\
\hline $\mathrm{Si}$ & 0.4 & 0.5 & 1.59 & 0.86 \\
$\mathrm{Mn}$ & 12.2 & 29.55 & - & 15.8 \\
$\mathrm{Nb}$ & 0.32 & 0.44 & 0.87 & 0.38 \\
\hline $\mathrm{Al}$ & - & - & 53.31 & - \\
\hline
\end{tabular}


Table 13: Top surface elemental composition of the coked samples for the PreO all CC (CA + PreS) runs with accelerating Voltage of $20 \mathrm{kV}$.

\begin{tabular}{ccccc}
\hline $\begin{array}{c}\text { PreO all CC (CA + PreS) } \\
\text { Elements }\end{array}$ & $\mathbf{2 5 / 3 5 ~ C r N i}$ & $\begin{array}{c}\mathbf{3 5 / 4 5} \\
\text { CrNi } \\
\text { coked samples (wt \%) }\end{array}$ & $\begin{array}{c}\text { Al- } \\
\text { containing }\end{array}$ & $\begin{array}{c}\mathbf{4 0 / 4 8} \\
\text { CrNi }\end{array}$ \\
\hline \hline $\mathrm{Ni}$ & 19.87 & 10.35 & 6.54 & 8.78 \\
\hline $\mathrm{Fe}$ & 21.45 & 14.56 & 11.23 & 1.85 \\
$\mathrm{Cr}$ & 42.2 & 62.16 & 15.2 & 65.8 \\
\hline $\mathrm{Si}$ & 5.36 & 1.98 & 4.89 & 2.67 \\
$\mathrm{Mn}$ & 10.23 & 10.2 & 2.89 & 18.36 \\
\hline $\mathrm{Nb}$ & 0.89 & 0.75 & 4.1 & 2.54 \\
\hline $\mathrm{Al}$ & - & - & 55.15 & - \\
\hline
\end{tabular}

Table 14: Top surface elemental composition of the coked samples for the PreO at $1223 \mathrm{~K}$ runs with accelerating Voltage of $20 \mathrm{kV}$.

\begin{tabular}{ccccc}
\hline $\begin{array}{c}\text { PreO at 1223 K (CA + PreS) } \\
\text { Elements }\end{array}$ & $\mathbf{2 5 / 3 5 ~ C r N i}$ & $\begin{array}{c}\mathbf{3 5 / 4 5} \text { CrNi } \\
\text { coked samples }(\text { wt \%) }\end{array}$ & $\begin{array}{c}\text { Al- } \\
\text { containing }\end{array}$ & $\begin{array}{c}\mathbf{4 0 / 4 8} \\
\text { CrNi }\end{array}$ \\
\hline \hline $\mathrm{Ni}$ & 17.6 & 9.36 & 8.63 & 8.3 \\
\hline $\mathrm{Fe}$ & 21.32 & 14.3 & 8.12 & 2.4 \\
\hline $\mathrm{Cr}$ & 46.36 & 64.98 & 17.23 & 63.96 \\
\hline $\mathrm{Si}$ & 3.65 & 1.65 & 3.65 & 2.14 \\
$\mathrm{Mn}$ & 10.07 & 8.91 & 2.36 & 20.8 \\
\hline $\mathrm{Nb}$ & 1 & 0.8 & 2.93 & 2.4 \\
\hline $\mathrm{Al}$ & - & - & 57.08 & - \\
\hline
\end{tabular}




\section{References}

(1). Paraskevas, P. D.; Sabbe, M. K.; Reyniers, M. F.; Papayannakos, N.; Marin, G. B., Kinetic Modeling of $\alpha$-Hydrogen Abstractions from Unsaturated and Saturated Oxygenate Compounds by Carbon-Centered Radicals. ChemPhysChem 2014, 15 (9), 1849-1866.

(2). Paraskevas, P. D.; Sabbe, M. K.; Reyniers, M.-F.; Papayannakos, N. G.; Marin, G. B., Kinetic Modeling of $\alpha$-Hydrogen Abstractions from Unsaturated and Saturated Oxygenate Compounds by Hydrogen Atoms. The Journal of Physical Chemistry A 2014, 118 (40), 92969309.

(3). Amghizar, I.; Dedeyne, J.; Brown, D. J.; Marin, G. B.; Van Geem, K. M., Sustainable innovations in steam cracking: $\mathrm{CO} 2$ neutral olefin production. Reaction Chemistry \& Engineering 2020, 5 (2), 239-257.

(4). Van Geem, K. M.; Galvita, V. V.; Marin, G. B., Making chemicals with electricity. Science 2019, 364 (6442), 734-735.

(5). Kivlen, J. A.; Koszman, I., Decoking of onstream thermal cracking tubes with h20 and h2. Google Patents: 1971.

(6). Sullivan, B. K., Ethylene Cracking Heater Decoking Tutorial. In AIChE Spring Natl. Meet., Conf. Proc., New Orleans, LA, 2014.

(7). Heynderickx, G.; Schools, E.; Marin, G., Optimization of the decoking procedure of an ethane cracker with a steam/air mixture. Industrial \& engineering chemistry research 2006, 45 (22), 7520-7529.

(8). Lenglet, E., Method of decoking an installation for steam cracking hydrocarbons, and a corresponding steam-cracking installation. Google Patents: 1993.

(9). HAK Decoking Technology (HDT).

http://www.a-hak-

is.com/en/home/what we do/services/furnace services/hak decoking technology hdt.

(10). Nunciato, D. J.; White, N. H.; Woodburn, W. A., Method for decoking fired heater tubes. Google Patents: 1981.

(11). Duvall, W. J., Decoking and cleaning tubular heaters. Google Patents: 1954.

(12). De Saegher, J. J.; Detemmerman, T.; Froment, G. F., Three dimensional simulation of high severity internally finned cracking coils for olefins production. Revue De L'Institut Français Du Pétrole 1996, 51 (2), 245-260.

(13). Detemmerman, T.; Froment, G. F., Three dimensional coupled simulation of furnaces and reactor tubes for the thermal cracking of hydrocarbons. Revue De L'Institut Français Du Pétrole 1998, 53 (2), 181-194.

(14). Schietekat, C. M.; van Goethem, M. W. M.; Van Geem, K. M.; Marin, G. B., Swirl flow tube reactor technology: An experimental and computational fluid dynamics study. Chemical Engineering Journal 2014, 238, 56-65.

(15). Torigoe, T.; Hamada, K.; Furuta, M.; Sakashita, M.; Otsubo, K.; Tomita, M. In Mixing element radiant tube (MERT) improves cracking furnace performance, 11th Ethylene Producers' Conference, Houston, TX, Houston, TX, 1999.

(16). Györffy, M.; Hineno, M.; Hashimoto, K.; Park, S.-H.; You, M.-S. In MERT performance and technology update, 21st Ethylene Producers' Conference, Tampa, FL, Tampa, FL, 2009.

(17). Schietekat, C. M.; Van Cauwenberge, D. J.; Van Geem, K. M.; Marin, G. B., Computational fluid dynamics-based design of finned steam cracking reactors. AIChE J. 2014, 60 (2), 794-808.

(18). Muñoz Gandarillas, A. E.; Van Geem, K. M.; Reyniers, M.-F.; Marin, G. B., Influence of the Reactor Material Composition on Coke Formation during Ethane Steam Cracking. Industrial \& Engineering Chemistry Research 2014, 53 (15), 6358-6371.

(19). Muñoz Gandarillas, A. E.; Van Geem, K. M.; Reyniers, M.-F.; Marin, G. B., Coking Resistance of Specialized Coil Materials during Steam Cracking of Sulfur-Free Naphtha. Industrial \& Engineering Chemistry Research 2014, 53 (35), 13644-13655. 
(20). Petrone, S.; L.Deuis, R.; Kong, F.; Unwin , P. In Catalyzed-assisted manufacture of olefins (CAMOL): Year-(4) update on commercial furnace installations, Proc. - Ethylene Prod. Conf., March 21-25; 2010.

(21). Schietekat, C. M.; Sarris, S. A.; Reyniers, P. A.; Kool, L. B.; Peng, W.; Lucas, P.; Van Geem, K. M.; Marin, G. B., Catalytic Coating for Reduced Coke Formation in Steam Cracking Reactors. Industrial \& Engineering Chemistry Research 2015, 54 (39), 9525-9535.

(22). Petrone, S.; Chen, Y.; Deuis, R.; Benum, L.; Saunders, R.; Wong, C. In Catalyzed-assisted manufacture of olefins (CAMOL): Realizing novel operational benefits from furnace coil surfaces, 20th Ethylene Producers' Conference, New Orleans, LA, New Orleans, LA, 2008.

(23). Wang, J.; Reyniers, M.-F.; Van Geem, K. M.; Marin, G. B., Influence of Silicon and Silicon/Sulfur-Containing Additives on Coke Formation during Steam Cracking of Hydrocarbons. Industrial \& Engineering Chemistry Research 2008, 47 (5), 1468-1482.

(24). Reyniers, M.-F.; Froment, G. F., Influence of metal-surface and sulfur addition on coke deposition in the thermal-cracking of hydrocarbons. Industrial \& Engineering Chemistry Research 1995, 34 (3), 773-785.

(25). Wang, J.; Reyniers, M.-F.; Marin, G. B., Influence of Dimethyl Disulfide on Coke Formation during Steam Cracking of Hydrocarbons. Industrial \& Engineering Chemistry Research 2007, 46 (12), 4134-4148.

(26). Reyniers, M.; Froment, G. F., Influence of metal-surface and sulfur addition on coke deposition in the thermal-cracking of hydrocarbons. Industrial \& Engineering Chemistry Research 1995, 34 (3), 773-785.

(27). Brown, D. E.; Clark, J. T. K.; Foster, A. I.; McCarroll, J. J.; Sims, M. L., Inhibition of Coke Formation in Ethylene Steam Cracking. In Coke Formation on Metal Surfaces, American Chemical Society: Michigan, United States, 1983; Vol. 202, pp 23-43.

(28). Wang, J.; Reyniers, M.-F.; Marin, G. B., The influence of phosphorus containing compounds on steam cracking of n-hexane. Journal of Analytical and Applied Pyrolysis 2006, 77 (2), 133-148.

(29). Vaish, S.; Kunzru, D., Triphenyl phosphite as a coke inhibitor during naphtha pyrolysis. Industrial \& Engineering Chemistry Research 1989, 28 (9), 1293-1299.

(30). Dhuyvetter, I.; Reyniers, M.-F.; Froment, G. F.; Marin, G. B.; Viennet, D., The influence of dimethyl disulfide on naphtha steam cracking. Industrial \& Engineering Chemistry Research 2001, 40 (20), 4353-4362.

(31). Bajus, M.; Vesely, V.; Baxa, J.; Leclercq, P. A.; Rijks, J. A., Steam cracking of hydrocarbons: 5. Effect of thiophene on reaction-kinetics and coking. Industrial \& Engineering Chemistry Product Research and Development 1981, 20 (4), 741-745.

(32). Bajus, M.; Vesely, V., Pyrolysis of hydrocarbons in the presence of elemental sulfur. Collection of Czechoslovak Chemical Communications 1980, 45 (1), 238-254.

(33). Bajus, M.; Baxa, J.; Leclercq, P. A.; Rijks, J. A., Steam cracking of hydrocarbons: 6. Effect of dibenzyl sulfide and dibenzyl disulfide on reaction-kinetics and coking. Industrial \& Engineering Chemistry Product Research and Development 1983, 22 (2), 335-343.

(34). Bajus, M.; Baxa, J., Coke formation during the pyrolysis of hydrocarbons in the presence of sulfur-compounds. Collection of Czechoslovak Chemical Communications 1985, 50 (12), 2903-2909.

(35). Depeyre, D.; Filcoteaux, C.; Blouri, B.; Ossebi, J. G., Pure n-nonane steam cracking and the influence of sulfur-compounds. Industrial \& Engineering Chemistry Process Design and Development 1985, 24 (4), 920-924.

(36). Dhuyvetter, I.; Reyniers, M. F.; Froment, G. F.; Marin, G. B.; Viennet, D., The influence of dimethyl disulfide on naphtha steam cracking. Industrial \& Engineering Chemistry Research 2001, 40 (20), 4353-4362. 
(37). Towfighi, J.; Sadrameli, M.; Niaei, A., Coke formation mechanisms and coke inhibiting methods in pyrolysis furnaces. J. Chem. Eng. Jpn. 2002, 35 (10), 923-937.

(38). Holmen, A.; Lindvaag, O. A.; Trimm, D. L., Coke formation during steam cracking of hydrocarbons .2. Effect of preoxidation and prereduction of the reactor surface. Journal of Chemical Technology and Biotechnology a-Chemical Technology 1985, 35 (7), 358-364.

(39). Jakobi, D.; Karduck, P. In Behavior of high-temperature tube materials in sulfurcontaining steam-cracking conditions, Corrosion 2018, Phoenix, Arizona, USA, 2018/7/20/; NACE International: Phoenix, Arizona, USA, 2018; p 17.

(40). Symoens, S. H.; Olahova, N.; Gandarillas, A. E. M.; Karimi, H.; Djokic, M. R.; Reyniers, M. F.; Marin, G. B.; Van Geem, K. M., State-of-the-art of Coke Formation during Steam Cracking: Anti-Coking Surface Technologies. Industrial \& Engineering Chemistry Research 2018, 57 (48), 16117-16136.

(41). Symoens, S. H.; Aravindakshan, S. U.; Vermeire, F. H.; De Ras, K.; Djokic, M. R.; Marin, G. B.; Reyniers, M. F.; Van Geem, K. M., QUANTIS: Data quality assessment tool by clustering analysis. International Journal of Chemical Kinetics 2019, 51 (11), 872-885.

(42). Sarris, S. A.; Olahova, N.; Verbeken, K.; Reyniers, M.-F.; Marin, G. B.; Van Geem, K. M., Optimization of the in-situ pretreatment of high temperature Ni-Cr Alloys for Ethane steam cracking. Industrial \& Engineering Chemistry Research 2017.

(43). Horsley, G. W.; Cairns, J. A., The Inhibition of Carbon Deposition on Stainless Steel by Prior Selective Oxidation. Appl. Surf. Sci. 1984, 18, 273.

(44). Luan, T. C.; Eckert, R. E.; Albright, L. F., Gaseous pretreatment of high-alloy steels used in ethylene furnaces: Pretreatment of incoloy 800. Industrial \& Engineering Chemistry Research 2003, 42 (20), 4741-4747.

(45). Jakobi, D.; Karduck, P.; Freiherr, V. R. A., The High-Temperature Corrosion Resistance of Spun-Cast Materials for Steam-Cracker Furnaces - A Comparative Study of Alumina- and Chromia-Forming Alloys. In NACE Corrosion 2013, 2013.

(46). Jakobi, D.; van Moesdijk, C.; Karduck, P.; von Richthofen, A., Tailor-made materials for high temperature applications: New strategies for radiant coil material development. Corrosion 2009.

(47). Asteman, H.; Hartnagel, W.; Jakobi, D., The Influence of Al Content on the High Temperature Oxidation Properties of State-of-the-Art Cast Ni-base Alloys. Oxid. Met. 2013, 80 (1-2), 3-12.

(48). Van Geem, K. M.; Dhuyvetter, I.; Prokopiev, S.; Reyniers, M. F.; Viennet, D.; Marin, G. B., Coke Formation in the Transfer Line Exchanger during Steam Cracking of Hydrocarbons. Industrial \& Engineering Chemistry Research 2009, 48 (23), 10343-10358.

(49). Gary Barone, M. H., David Smith , Restek Corporation Performance Coatings; Shawn Rowan, W. J. G., O'Brien Corporation; Phil Harris, H. L. Sulfinert ${ }^{\circledR}$ Treated Systems Preserve ppb Levels of Active Sulfur Compounds.

(50). Sarris, S. A.; Patil, M.; Verbeken, K.; Reyniers, M.-F.; Van Geem, K. M., Effect of longterm high temperature oxidation on the coking behavior of $\mathrm{Ni}-\mathrm{Cr}$ superalloys. Materials 2018, $10(11)$.

(51). Olahová, N.; Sarris, S. A.; Reyniers, M.-F.; Marin, G. B.; Van Geem, K. M., Coking Tendency of 25Cr-35Ni Alloys: Influence of Temperature, Sulfur Addition, and Cyclic Aging. Industrial \& Engineering Chemistry Research 2018, 57 (9), 3138-3148.

(52). Levin, I.; Brandon, D., Metastable Alumina Polymorphs: Crystal Structures and Transition Sequences. Journal of the American Ceramic Society 2005, 81, 1995-2012. 